\title{
Bovine Serum Albumin Adsorption at a Silica Surface Explored by Simulation and Experiment
}

\author{
Karina Kubiak-Ossowska ${ }^{a^{*}}$, Karolina Tokarczyk ${ }^{b}$, Barbara Jachimska ${ }^{b}$ and Paul A. Mulheran ${ }^{a}$ \\ ${ }^{a}$ Department of Chemical and Process Engineering, University of Strathclyde, James Weir \\ Building, 75 Montrose Street, Glasgow G1 1XJ, UK. \\ *e-mail: karina.kubiak@strath.ac.uk \\ bJ. Haber Institute of Catalysis and Surface Chemistry, Polish Academy of Science (PAS), \\ Niezapominajek 8, 30-239 Cracow, Poland
}

\begin{abstract}
Molecular details of BSA adsorption on a silica surface are revealed by fully atomistic Molecular Dynamics (MD) simulations (with a $0.5 \mu$ s trajectory), supported by Dynamic Light Scattering (DLS), Zeta Potential, Multi-Parametric Surface Plasmon Resonance (MP-SPR) and Contact Angle experiments. The experimental and theoretical methods complement one another and lead to a wider understanding of the mechanism of BSA adsorption across a range of $\mathrm{pH}$ 3-9. The MD results show how the negatively charged $\mathrm{BSA}$ at $\mathrm{pH} 7$ adsorbs to the negatively charged silica surface, and reveal a unique orientation with preserved secondary and tertiary structure. The experiments then show that the protein forms complete monolayers at $\sim \mathrm{pH} 6$, just above the protein's isoelectric point (pH5.1). The surface contact angle is maximum when it is completely coated with protein, and the hydrophobicity of the surface is understood in terms of the simulated protein conformation. The adsorption behaviour at higher $\mathrm{pH}>6$ is also consistently interpreted using the MD picture; both the contact angle and the adsorbed protein mass density decrease with increasing $\mathrm{pH}$, in line with the increasing magnitude of negative charge on both the protein and the surface. At lower $\mathrm{pH}<5$ the protein starts to unfold, and the adsorbed mass dramatically decreases. The comprehensive picture that emerges for the formation of oriented protein films with preserved native conformation will help guide efforts to create functional films for new technologies.
\end{abstract}




\section{INTRODUCTION}

Proteins play a key role in numerous material systems related to health-care technologies, and control of protein adsorption at various surfaces is crucial in modern medicine, biology and technology. ${ }^{1}$ To control protein adsorption, we require detailed understanding of the protein - surface interactions, including solvent effects at the surface such as water conformation and the distribution of ions. Bovine Serum Albumin (BSA) adsorption at silica $\left(\mathrm{SiO}_{2}\right)$ surfaces is a good model system to develop this understanding: BSA is one of the most widely studied proteins, and protein adsorption properties on silica has attracted growing interest for its applications in nanomedicine as a carrier for therapeutic protein delivery ${ }^{2}$ as well as enzyme immobilization and biocatalytic applications. ${ }^{3-4}$

BSA is composed of 583 aminoacids that create 29 a-helices. ${ }^{5}$ It is a heart-shaped protein divided into three domains, with each domain further divided into two subdomains (Figure 1). All but one of the protein's thirty five cysteine (Cys) residues are involved in seventeen disulphide bridges, among which there are eight double disulphide bridges. ${ }^{5}$ This extended disulphide bridge network is responsible for BSA's ability to recover its shape and structure; BSA is classified as a soft-protein, ${ }^{6}$ so that changes to its tertiary structure when binding to substrates are readily reversed when the substrate is released. Moreover, contrary to enzymatic albumins classified as hard-proteins (for example lysozyme) the structure of soft-proteins is significantly influenced by solution $\mathrm{pH}$. This ability is crucial for BSA's technological potential for binding, transporting and releasing various drugs, ${ }^{5,7-9}$ fatty acids, ${ }^{10}$ flavonoids ${ }^{11}$ and other molecules such as gold nanoparticles. ${ }^{12}$

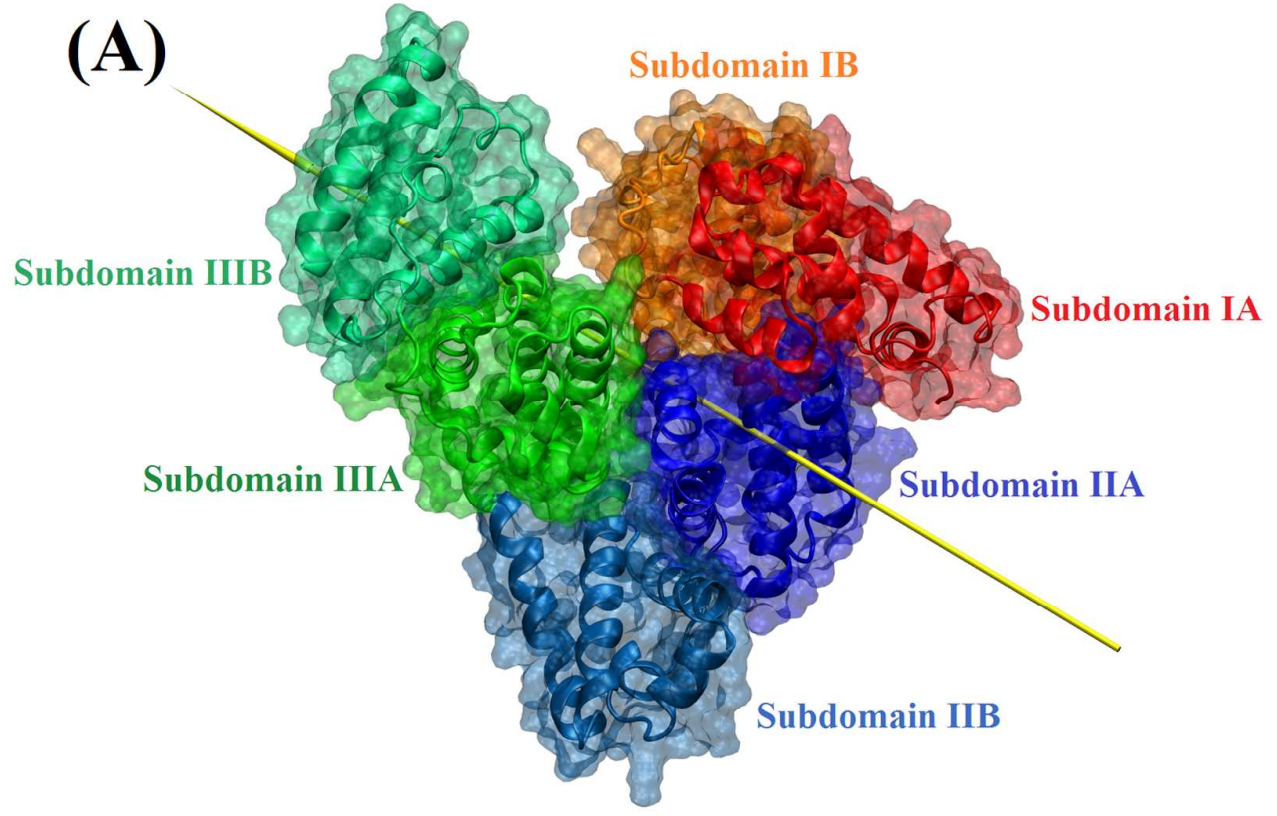




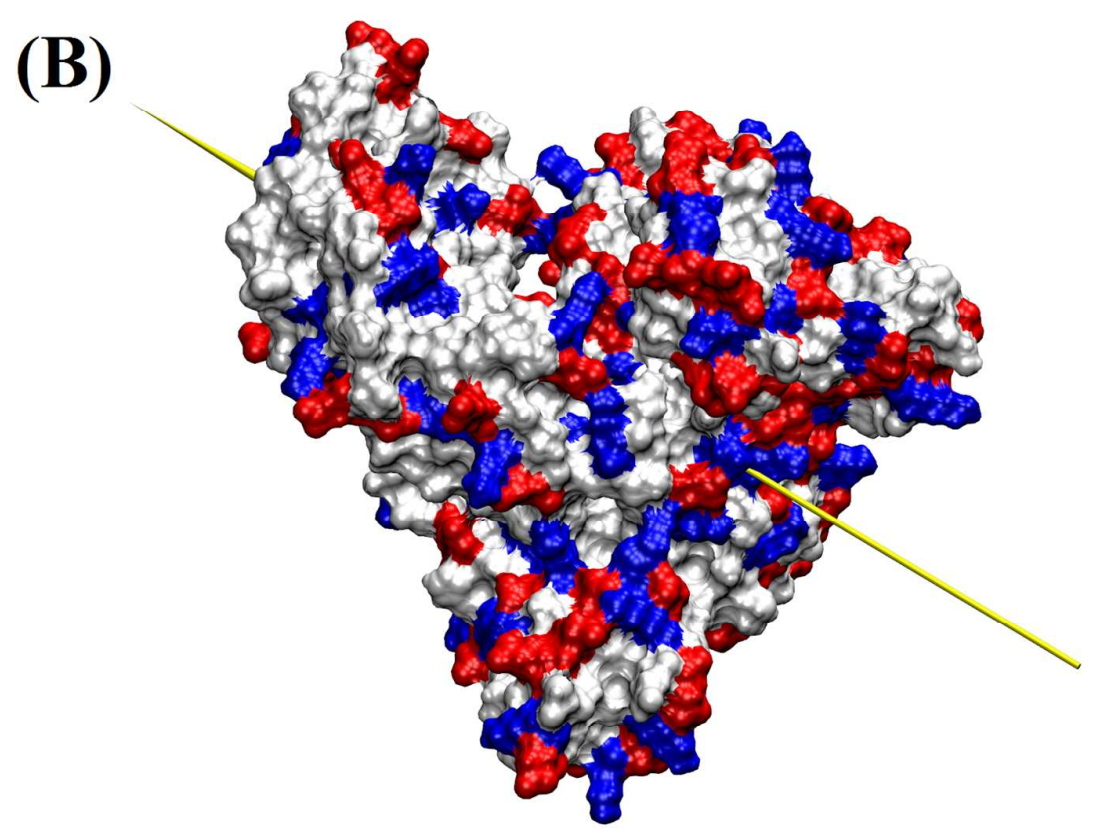

\section{(C)}

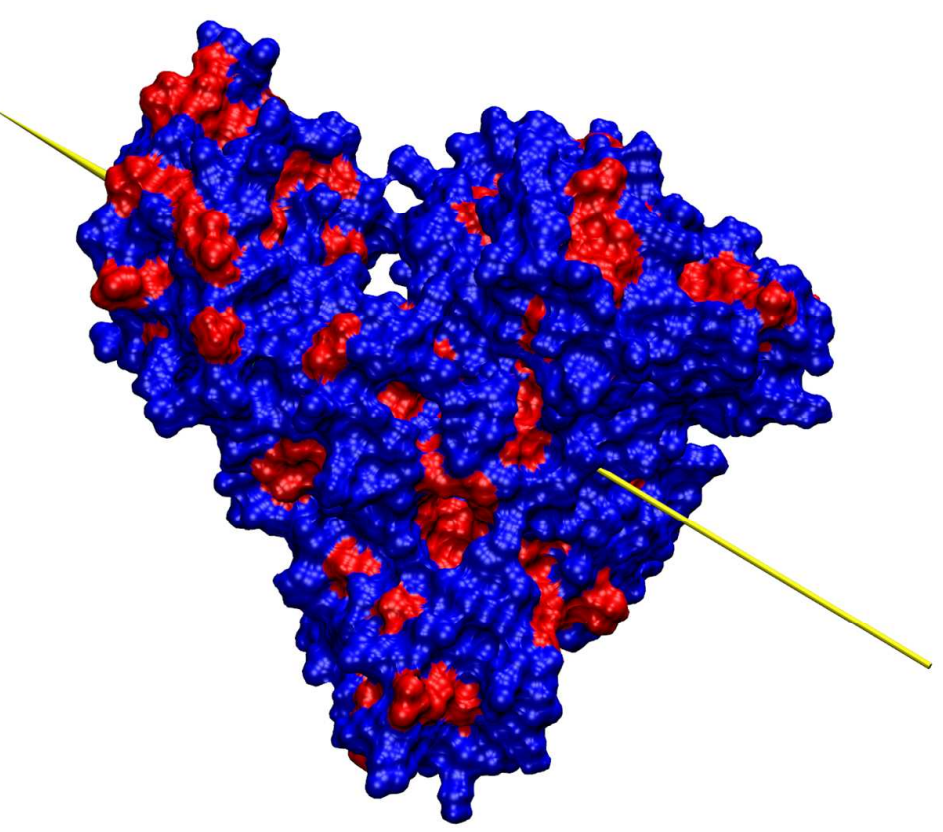

Figure1. BSA structure (A), and the distribution of charge (B) and hydrophobicity (C) on its surface. In Fig. (A) the protein "ghost" surface is shown alongside the secondary structure elements represented by "cartoon" as defined in VMD. ${ }^{13}$ Domain I is indicated by red-related colors (IA - red, IB - orange), domain II by blue-related colors (IIA - blue, IIB - light blue) and domain III by green-related colors (IIIA - green, IIIB - lime). The color scheme follows that introduced by Majorek et al. ${ }^{5}$ All subdomains are annotated and the yellow arrow indicates the protein dipole moment. In (B) and (C) the protein surface is solid and colored by residues' total charge (positive-blue, negative-red, neutral-white) and hydrophobicity (hydrophobic-red, hydrophilic-blue), respectively. The hydrophobicity map was produced using the hydrophaty index. ${ }^{14}$ 
Recent experimental BSA adsorption studies ${ }^{15-20}$ have revealed numerous interesting phenomena regarding this protein's behaviour at the surface. However, even modern experimental techniques in isolation have limited access to molecular details such as:

(i) Identifying the most important residues and their interactions with the surface, the water and the ions close to the surface;

(ii) Understanding how a negatively protein such as $\mathrm{BSA}$ at $\mathrm{pH} 7$ can adsorb to a negatively charged surface such as silica at $\mathrm{pH} 7$;

(iii) Determining the final protein orientation and conformation on the surface;

(iv) Distinguishing the roles of the various forces and interactions;

(v) Assessing the adsorbed protein's mobility and diffusion pathways on the surface;

(vi) Compiling a complete molecular-scale picture of the structure and properties of adsorbed protein layers.

These questions can be addressed by theoretical techniques such as Molecular Dynamics (MD) simulations, which in turn help us to interpret experimental observations and attain a deeper understanding of the adsorption process.

MD results for BSA dynamics with various additives ${ }^{12,21-22}$ as well as BSA adsorption on graphite, ${ }^{23}$ carbon nanotubes ${ }^{24}$ and polyoxyethylene ${ }^{25}$ have been recently published. We have also published key aspects of the initial stages of $\mathrm{BSA}$ adsorption on $\mathrm{SiO}_{2} \cdot{ }^{26}$ Here we complement our fully atomistic MD results of $\mathrm{BSA}$ adsorption at a $\mathrm{SiO}_{2}$ surface with a further analysis of the protein's behaviour on the surface, and use this to interpret experimental results for the system including Dynamic Light Scattering (DLS), Zeta potential, MultiParametric Surface Plasmon Resonance (MP-SPR) and contact angle measurements. In combination, we are able to address the questions (i)-(vi) listed above, demonstrating the power of our approach to exploit complementary techniques to reveal crucial understanding of the complex BSA-silica adsorption process across a range of $\mathrm{pH}$ 5-9.

\section{MATERIALS AND METHODS}

\section{MD simulations}

As described previously, ${ }^{26}$ all simulations were performed with the NAMD $2.8^{27}$ package using the CHARMM27 force-field, and analyzed using VMD. ${ }^{13} 3 \mathrm{~V} 3^{5}$ with all disulphide bridges kept was used as the starting BSA structure. Note that the first two residues are missing in the pdb structure, so the total number of residues in the model is 581 rather than 583 , with the numbering started at 3 . The missing residues do not influence the BSA structure, total charge, or overall hydrophaty index (the hydrophaty index of a residue indicates its relative hydrophobicity, with more hydrophobic residues having more positive indices) ${ }^{14}$. We identified a successful adsorption trajectory previously ${ }^{26}$ and here we have extended this trajectory for an additional 300ns (so the total length of this fully atomistic trajectory is $0.5 \mu \mathrm{s})$. We note that the multiple unsuccessful adsorption trajectories reported previously ${ }^{26}$ suggest that negative protein adsorption (at $\mathrm{pH}$ ) on a negative surface is a rare event, at least on the accessible time scale of fully atomistic MD.

The protein $\left(-17\right.$ e at $\mathrm{pH} 7$ ) was initially neutralized by $\mathrm{NaCl}$ at an ionic strength $\mathrm{I}=5 \times 10^{-}$

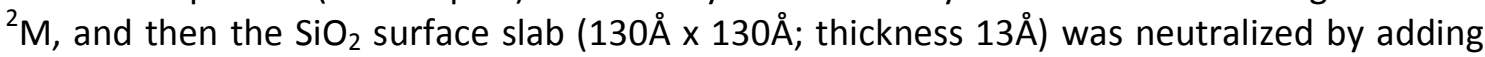
$429 \mathrm{Na}^{+}$ions. The total ion count in the system was $466 \mathrm{Na}^{+}$and $21 \mathrm{Cl}^{-}$while total system charge was $-1.05 \times 10^{-6}$ e (i.e. neutral). The silica surface model was constructed similarly to our previous work ${ }^{28-30}$ using a (101) slab of $\alpha$-crystabolite, and as in ref $^{26}$ the slab has been cut from a bulk crystal in such a way as to leave siloxide groups (三SiO- ) both at the top and 
bottom of the slab. The charge of the slab used was -429 e. Note that in the experiments at $\mathrm{pH} 7.0$, the silica has a negative zeta potential (see below in Results Section and also refs $^{16,18,30-33}$ ) suggesting that the setup of the model mimics experimental conditions.

We employ a large periodic cell to accommodate the BSA which is $~ 80 \AA-90 \AA$ in diameter. Furthermore, for the adsorption simulation the protein needs to start at least $20 \AA$ from the surface and its image. Hence, we utilise a simulation cell of the size $~ 130 \AA x 130 \AA x$ $190 \AA$, filled by water (TIP3P model) in addition to the silica slab, the protein and the ions. The total number of atoms in the cell was $\sim 240,000$.

We initially ran water and ion energy minimization followed by equilibration at a constant temperature of $300 \mathrm{~K}$ for $100 \mathrm{ps}$, with integration time step $1 \mathrm{fs}$. Next we minimized the energy of the entire system (water, ions and protein) for 10,000 steps and then equilibrated it to $300 \mathrm{~K}$ for $6 \mathrm{~ns}$. The NVT production trajectory analysed here was $500 \mathrm{~ns}$ long with time-step $2 \mathrm{~ns}$. In all stages the surface atoms were kept immobile. For electrostatic interactions the PME method was used, ${ }^{34}$ and the VdW cutoff was $12 \AA$. To obtain the desired pressure of $1 \mathrm{~atm}$ a flexible periodic cell was used. To reduce the computational time all bonds and angles in the water molecules were constrained.

Steered Molecular Dynamics (SMD) simulations with constant velocity pulling at $0.005 \AA$ /ps were started from the adsorption state found in the adsorption trajectory. We prepared 4 different runs where the Lys537 $C_{\gamma}$ atom only was pulled in 4 various directions. The SMD spring constant was $k=278 \mathrm{pN} / \AA$, with all other settings as in the traditional MD. We estimate the energy of diffusion and adsorption from the appropriate force-distance curves following previous work. ${ }^{35}$

\section{Experiments \\ Materials}

In this work, Bovine Serum Albumin (BSA) purchased from Aldrich (Cat. no. A0281 >99\% protein, essentially fatty-acid free) was used. All BSA solutions were freshly prepared prior to the experiments by dissolving the protein powder in an aqueous solution. The $\mathrm{pH}$ was controlled by adding hydrochloric acid $(\mathrm{HCl})$ or sodium hydroxide $(\mathrm{NaOH})$ solutions and the ionic strength was adjusted using sodium chloride $(\mathrm{NaCl})$. All measurements were performed at a controlled temperature of $298 \pm 0.1 \mathrm{~K}$.

The $\mathrm{pH}$ of the BSA solution was monitored over a concentration range of 20010,000ppm (Figure S1, Supplementary Materials) using a precision WTW pH meter equipped with the Hamilton Polyplast Din electrode. The $\mathrm{pH}$ was found to reach a plateau at the concentration equal 6000ppm ( $\mathrm{pH}=6.8) ; \mathrm{pH}$ around 7.0 is natural for BSA.

\section{Dynamic Light Scattering (DLS) and Zeta Potential measurements}

The diffusion coefficient of BSA in bulk solution was determined using dynamic light scattering with a Malvern Nano ZS instrument. From the diffusion coefficient value, the hydrodynamic radius was calculated using Stoke's formula. ${ }^{36-37}$

The zeta potential of the protein was obtained as a function of $\mathrm{pH}(2.5-10.5)$ and ionic strength $\left(I=1 \times 10^{-3} \mathrm{M} ; \mathrm{I}=5 \times 10^{-3} \mathrm{M} ; \mathrm{I}=1 \times 10^{-2} \mathrm{M} ; \mathrm{I}=0.15 \mathrm{M}\right)$ using a Zetasizer Nano ZS Malvern system. ${ }^{36}$ The zeta potential of the silica surface was determined using the Surface Zeta Potential Cell (ZEN 1020) from Malvern Instruments, as described in our earlier work; ${ }^{18,30}$ the sample was placed between two palladium electrodes in a measurement cell, which can be mounted at a desired height. Then the zeta potential was measured using a standard cuvette for DLS measurements. 


\section{Multi-Parametric Surface Plasmon Resonance (MP-SPR)}

Adsorption of $\mathrm{BSA}$ onto the $\mathrm{SiO}_{2}$ surface was monitored using the optical method MP-SPR (BioNavis SPR NaviTM 200, BioNavis Ltd, Finland). The MP-SPR instrument with the Kretschmann configuration and angle-scanning goniometer is equipped with two different wavelengths $(\lambda=670 \mathrm{~nm}$ and $\lambda=785 \mathrm{~nm})$ and two fluidic channels. The angular range is 40 to 78 degrees. Liquid flow conditions can be controlled with a peristaltic pump.

Changes in SPR angle were used to determine the mass adsorbed on the sensor surface according to the equation:

$$
\Gamma_{\mathrm{MP}-\mathrm{SPR}}=\frac{\Delta \Theta \times \mathrm{k} \times \mathrm{d}_{\mathrm{BSA}}}{d n / d c}
$$

where $\Delta \Theta$ is the change in the SPR angle, $k$ is an instrument constant, $d_{B S A}$ is the thickness of the adsorbed BSA layer, and $d n / d c$ is the refractive index increment; $k x d_{B S A} \approx 1.0 \times 10^{-7} \mathrm{~nm} / \mathrm{deg}$ for $\lambda=670 \mathrm{~nm}$. The refractive index increment characterizes the change of the refractive index $n$ with the concentration $c$, and was measured with an Atago Refractometer RX-5000 $\alpha$. For the BSA solution, $d n / d c \approx 0.116 \mathrm{~cm}^{3} / \mathrm{g}$ (with I $=1 \times 10^{-2} \mathrm{M} \mathrm{NaCl}$ ).

We used a silica-coated MP-SPR sensor, which was cleaned using Hellmanex solution 0.5\% (Hellma Analytics) and then rinsed with water before each experiment. The BSA layer was grown on the silica by flowing the protein solution (concentration $5 \mathrm{ppm}, \mathrm{I}=1 \times 10^{-2} \mathrm{M}$ $\mathrm{NaCl}, \mathrm{pH}$ range 3.0 to 9.0 ) through the cell for $30 \mathrm{~min}$. The MP-SPR sensor was then rinsed with the electrolyte solution for $30 \mathrm{~min}$.

\section{Contact angle measurements}

The contact angle measurements were performed by using an axisymmetric drop shape analysis (ADSA) system. ${ }^{38}$ Measurements of the contact angle for the BSA layers formed on the silica surface were carried out for $\mathrm{pH}$ range $3.0-9.0$ and ionic strength $1 \times 10^{-2} \mathrm{M} \mathrm{NaCl}$ after an adsorption time of 5 or $150 \mathrm{~min}$ to monitor early and matured adsorption state.

\section{RESULTS AND DISCUSSION}

\section{SIMULATIONS RESULTS}

\section{Protein structural features}

BSA at pH7 contains numerous charged aminoacids: Arg and Lys are positively charged while Asp and Glu are negative. The total charge of the protein is -17 e, nevertheless as apparent in Fig. $1 \mathrm{~B}$ the charge is not distributed equally between the domains and subdomains; subdomain IA has charge -10e and subdomain IIIA has +3 e (see Table 1). This non-uniform charge distribution yields a large dipole moment of 650D across the protein in solution, oriented from subdomain IIA to IIIB. In Fig. $1 \mathrm{C}$ it is also apparent that IIIB is the most hydrophobic subdomain in BSA, with hydrophaty index $-15.6^{14}$ (see Table 1 ).

This is an interesting observation, since as we have demonstrated previously, ${ }^{26} \mathrm{IIIB}$ is the subdomain facing the silica surface during and after adsorption. There is an agreement in the literature that electrostatics is a key driver for protein adsorption. ${ }^{15,31,39-44}$ However, while in mid $\mathrm{pH}$ the main driving force for hen egg white lysozyme adsorption on $\mathrm{SiO}_{2}$ surface is electrostatics, at high or low $\mathrm{pH}$, when the protein and/or surface charge is negligible, hydrophobic interactions start to be important. ${ }^{30}$ Therefore, protein adsorption seems to be governed by two forces, strong electrostatic and weaker hydrophobic forces; 
1

2

3

4

5

6

7

8

9

depending on the environmental conditions, one of them can dominate, but in more complicated cases both can be important.

The fact that the BSA dipole moment points towards subdomain IIIB, which is only slightly negative in comparison to other subdomains and relatively hydrophobic, suggests that in the case of BSA adsorption at $\mathrm{SiO}_{2}$ both electrostatic and hydrophobic forces may play important roles.

Table 1. BSA charged and hydrophobic residues by subdomain, domain and full protein. The second column lists the number of residues per structure, while the following lists the number of hydrophilic, hydrophobic, charged, positive and negative residues. The last two columns list total charge and hydrophathy index per structure.

\begin{tabular}{|c|c|c|c|c|c|c|c|c|}
\hline \multirow[t]{2}{*}{ Structure } & \multicolumn{6}{|c|}{ Number } & \multirow{2}{*}{$\begin{array}{l}\text { Total } \\
\text { charge }\end{array}$} & \multirow{2}{*}{$\begin{array}{l}\text { Hydrophaty } \\
\text { index }\end{array}$} \\
\hline & Residues & Hydrophobic & Hydrophilic & Charged & Positive & Negative & & \\
\hline IA & 105 & 41 & 64 & 32 & 11 & 21 & -10 & -57.5 \\
\hline IB & 86 & 29 & 57 & 27 & 13 & 14 & -1 & -68.1 \\
\hline 1 & 191 & 70 & 121 & 59 & 24 & 35 & -11 & -119.3 \\
\hline IIA & 103 & 43 & 60 & 37 & 19 & 18 & +1 & -50.2 \\
\hline IIB & 88 & 34 & 54 & 28 & 10 & 18 & -8 & -49.6 \\
\hline II & 191 & 77 & 114 & 65 & 29 & 36 & -7 & -99.8 \\
\hline IIIA & 113 & 41 & 72 & 29 & 16 & 13 & +3 & -40.3 \\
\hline IIIB & 86 & 39 & 47 & 26 & 12 & 14 & -2 & -15.6 \\
\hline III & 199 & 54 & 145 & 55 & 28 & 27 & +1 & -55.9 \\
\hline BSA & 581 & 227 & 354 & 179 & 81 & 98 & -17 & -275 \\
\hline
\end{tabular}

\section{Water and ion layer structure on the surface}

To understand the BSA adsorption mechanism, first we have to consider the structure created by water and ions in close proximity to the $\mathrm{SiO}_{2}$ surface. As in our study of $\mathrm{HEWL}$ adsorption on mica, ${ }^{40}$ two well-defined water layers formed on the $\mathrm{SiO}_{2}$ surface (Fig. 2). Due to the large number of ions in the system, the outer water layer is disrupted by the $\mathrm{Na}^{+}$ions; the smallest distance to an oxygen atom of the $\mathrm{SiO}_{2}$ surface is $5.2 \AA$ (Fig. $2 \mathrm{~A}$ ), while the most typical distance between the surface and sodium layer is around $6 \AA$. Due to their size, $\mathrm{Na}^{+}$ ions were not able to pass between the water layers and penetrate closer to the surface. The thickness of each water layer was $1.5 \AA$, and the closest distance between oxygen from $\mathrm{SiO}_{2}$ and water hydrogen was $3.3 \AA \AA$. Due to the fact that the $\mathrm{SiO}_{2}$ surface is not smooth on this scale, the water layers are also "waved", as shown in Fig. 2. Above the outer water layer, freely diffusing bulk water is observed. 
(A) $\mathrm{O}^{\mathrm{Na}}$
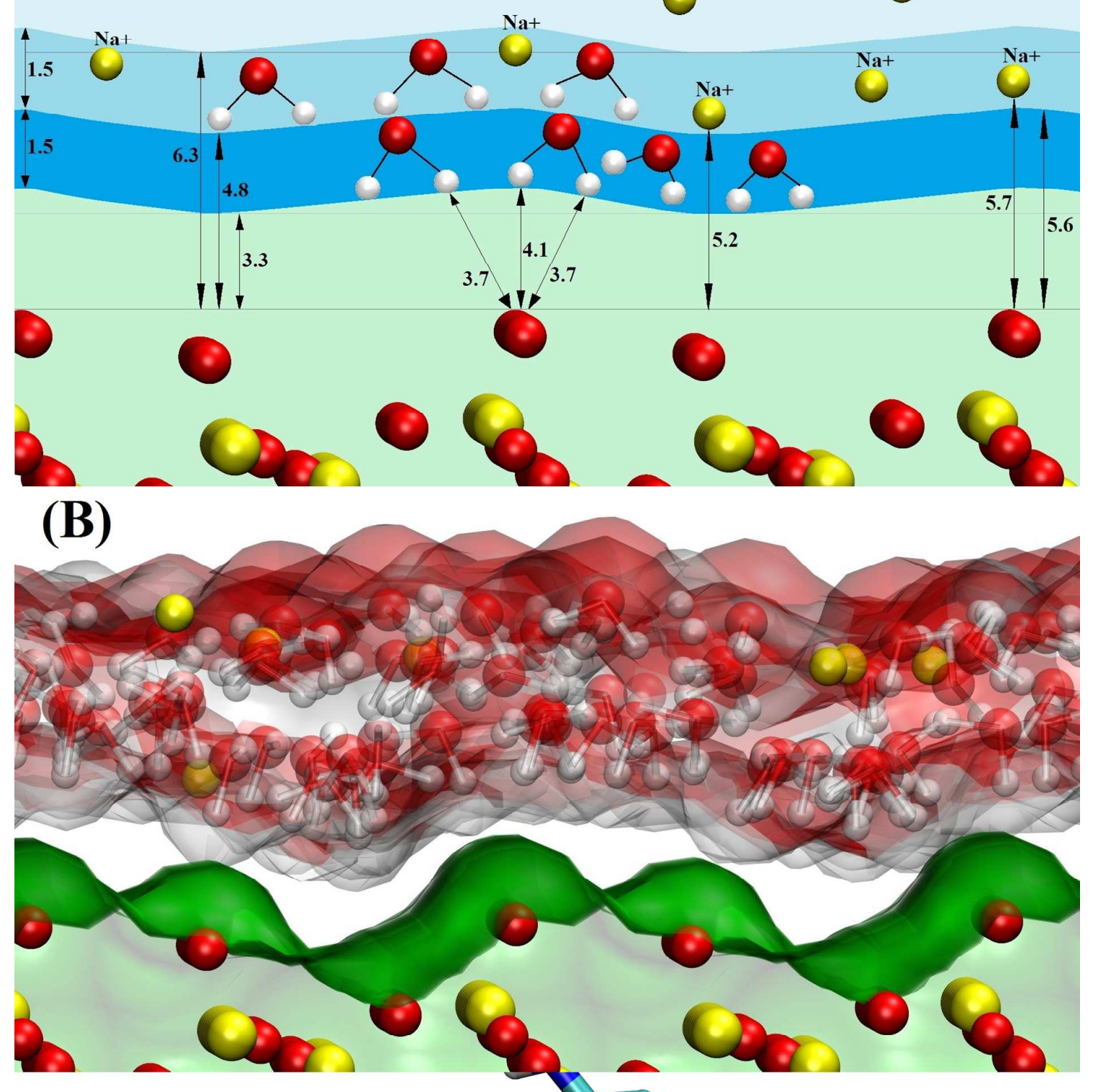

(C)

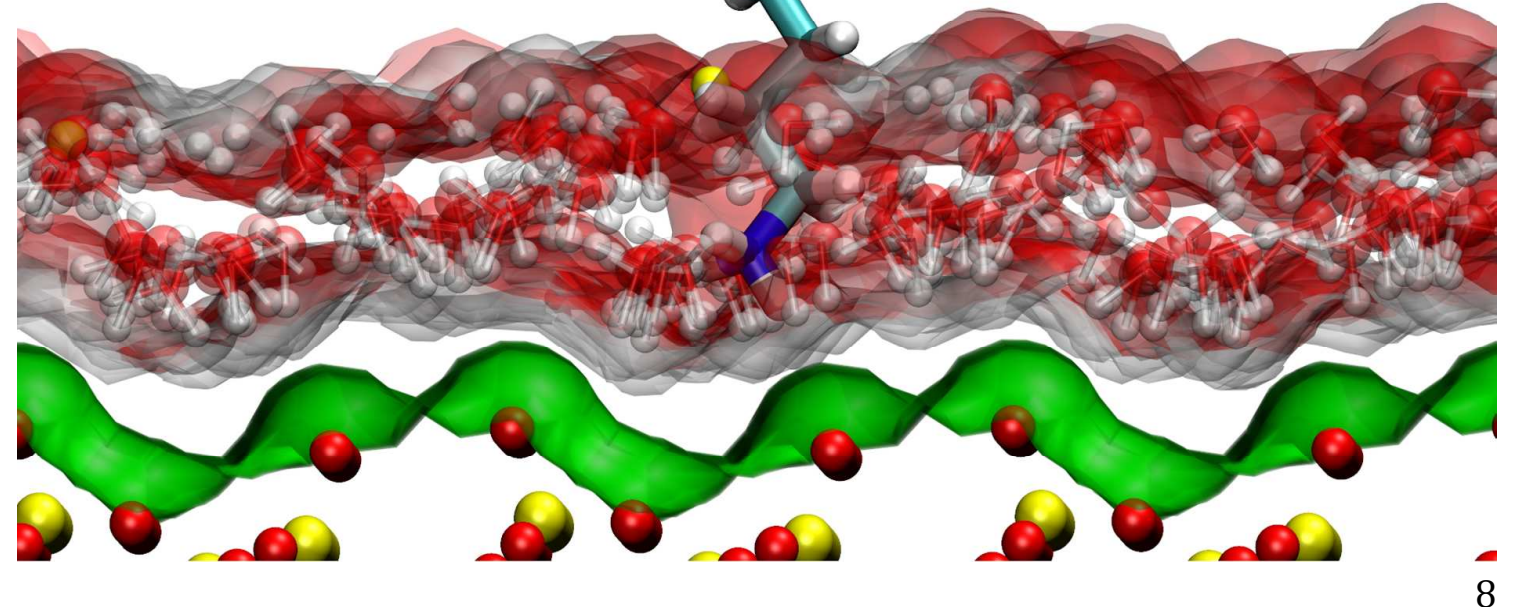

ACS Paragon Plus Environment 
Figure 2. Water layers created at the $\mathrm{SiO}_{2}$ surface. (A) Schematic view of water and $\mathrm{Na}^{+}$ layer. All atoms are shown as $\mathrm{CPK}$ in $\mathrm{VMD},{ }^{13}$ oxygen atoms are indicated by red, hydrogen by white, silica and sodium by yellow. The area is divided into the "surface", the light green part of the scheme, the inner water layer (dark blue), outer water layer (light blue) and bulk (very light blue). Sodium ions are additionally annotated as well as all the distances between top of the surface atoms and the layers. For clarity, only a few water molecules are shown explicitly. (B) Water and $\mathrm{Na}^{+}$layer snapshot from the simulation. The color code for atoms and surface area is as in (A), while the water layers are shown by a transparent surface colored by name. (C) The surface layer disruption by the adsorbing Lys537 residue. Lys is shown by licorice ${ }^{13}$ and colored by name.

When the protein has adsorbed, we typically observe an anchoring residue penetrating through the water layers. Various MD studies indicate that positively charged Arg plays this role effectively ${ }^{29-30,35,40,43-47}$ However, BSA's 23 Arg are mostly involved in intramolecular interactions and are not free to play a role in surface adsorption. Instead, the positively charged (at pH7) Lys residues play this role, and Lys573 and Lys537 were observed to be able to penetrate both water layers and interact directly with the $\mathrm{SiO}_{2}$ surface. ${ }^{26}$ To adsorb, the Lys residue has to replace 2-3 water molecules from each water layer, those molecules then migrate to the bulk water. Additionally, the $\mathrm{Na}^{+}$ion has to migrate to another region within the water-ion surface structure. $\mathrm{Na}^{+}$is usually "caught" by the nearby negatively charged Glu residue.

Over 20 years ago Durell et al concluded that the main interaction of $\mathrm{SiO}_{2}$ and $\mathrm{TiO}_{2}$ (both hydrophilic) with globular proteins has to be via $\mathrm{H}$-bonds, possibly involving water molecules simultaneously bonded to both protein and the surface. ${ }^{48}$ Kurrat et al, who studied BSA adsorption kinetics on silica-titania surfaces, also concluded that around 4-5 Hbonds created between BSA and the surface (or surface water) are enough to immobilize the BSA on the surface, while $6 \mathrm{H}$-bonds are required to change the adsorption behaviour from reversible to irreversible. ${ }^{49}$ Therefore, our observation that only a few residues act as anchors for the protein adsorption is reasonable. ${ }^{26} \mathrm{H}$-bonds with the outer water layer are expected to be necessary for $\mathrm{BSA}$ adsorption on $\mathrm{SiO}_{2}$, while $\mathrm{H}$-bonds with the inner water layer would likely result in irreversible adsorption.

\section{The BSA Adsorption Pathway}

In ref ${ }^{26}$ we presented the adsorption stages from the adsorption trajectory, and we summarize them here for clarity:

1) Stage $A(0-50 \mathrm{~ns})$ : BSA diffuses freely in the water without interacting with the silica surface; it is sufficiently far from the surface for the long-range electrostatics to be screened by the counter ions in solution.

2) Stage B (50ns - 91.2ns): BSA diffuses closer to the surface, presenting its IIIB subdomain so that it is attracted to the surface.

3) Stage C (91.2ns $-100.88 \mathrm{~ns})$ : BSA is initially adsorbed (using the positively charged Lys573) and temporarily immobilized.

4) Stage $D(100.88 n s-159 n s)$ : BSA desorbs from this initial position.

5) Stage E (159ns - 186ns): BSA starts to re-adsorb, rotating to reach a preferred orientation with respect to the surface; Lys537 passes through the surface water layers.

6) Stage $F(186 n s-200 n s)$ : BSA is adsorbed. 
Following our analysis of the extended trajectory in the adsorbed stage $F$, we can add a further statement:

7) Stage M (>200ns): BSA diffuses on the surface, but does not desorb; instead the protein switches spontaneously between the configurations of $M$ and $F$ from 200ns-500ns, showing no sign of ceasing this switching behaviour.

Snapshots from various time-points in the trajectory are shown in Fig. 3, and the Supplementary Information contains a movie of the adsorption trajectory.

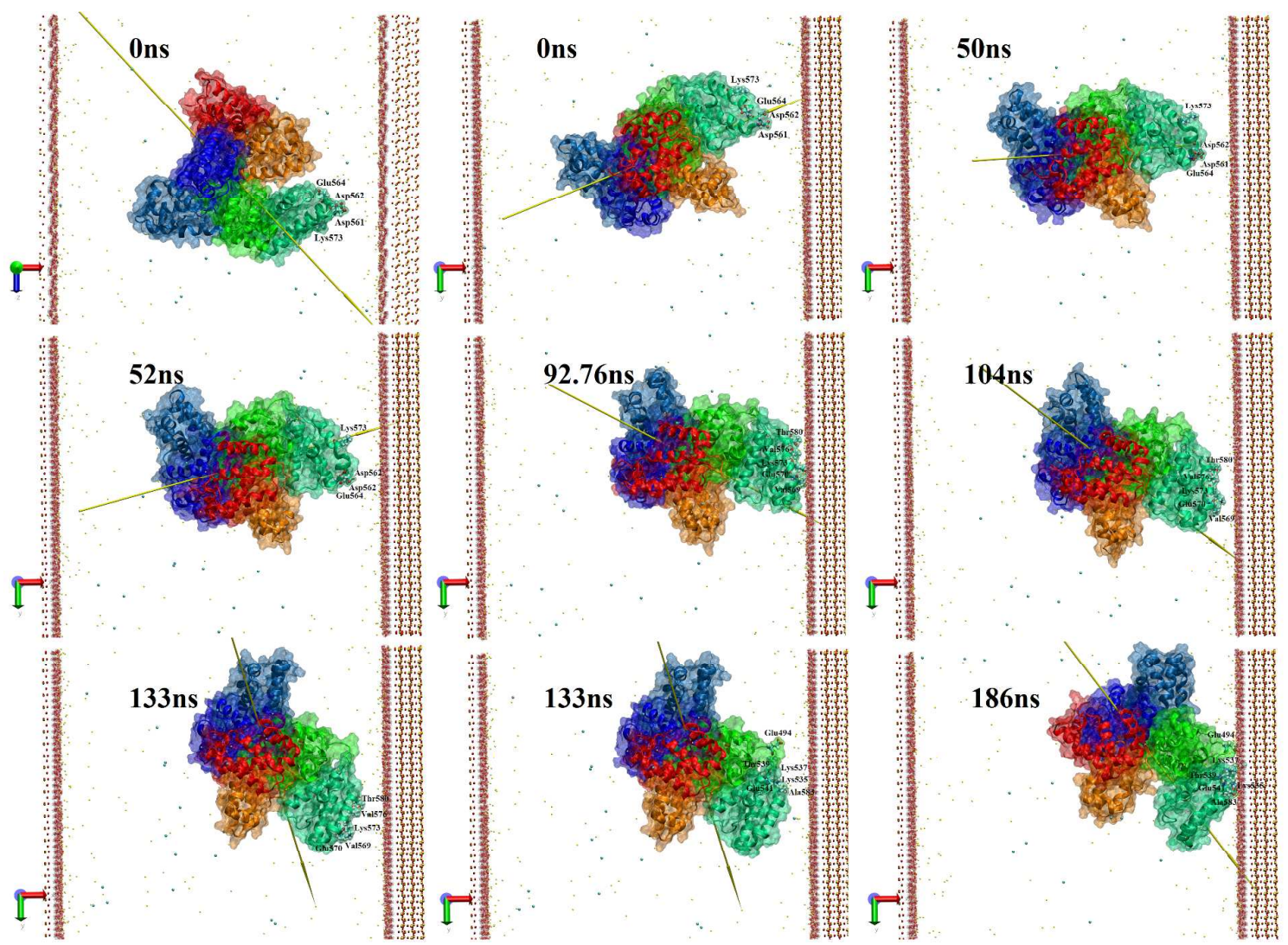

Figure 3. Snapshots illustrating the adsorption trajectory. The protein color scheme follows that on Figure 1. The key residues are shown by the licorice representation as defined in $\mathrm{VMD}^{13}$ and colored by name (oxygen-red, carbon-cyan, nitrogen-blue, hydrohen-white) and annotated. The oxygen of the silica surface is also red while silicon is yellow. The water has red oxygen and white hydrogen, with yellow sodium and blue chlorine ions. For clarity only the water in the surface layers are shown. For time Ons and 133ns two snapshots are presented. Snapshots at Ons show different orientations in space (see the axis at bottom left corner) while the former (133ns) shows different selection of important residues. Snapshots for the remaining $0.5 \mu$ s do not differ much from that at $186 \mathrm{~ns}$ and so are not shown.

The centre-of-mass (COM) plots shown in Fig. 4 reflect the protein mobility across the surface plane (A) alongside its distance from the surface (B). The stages of the adsorption above are labeled in these plots, where we also extend the time scale to 500ns from the original 200ns reported earlier. ${ }^{26}$ In particular, note the new mobility stages $M$.

At $186 \mathrm{~ns}$ of the trajectory, the BSA is in its final adsorption stage (Stage F). The list of key residues for the BSA-silica surface interactions includes: Glu494, Thr495, Lys535, Lys537, Thr539, Glu541, Gln542, Thr580 and Ala583 (see Table 2). This list is maintained in all 
subsequent adsorption states. Glu is negatively charged, Lys is positively charged, Thr is neutral and Ala583 possess negative partial charge because it is the C-terminal residue. All these residues, apart from the Ala side chain, are hydrophilic and able to interact with water. Nevertheless, there are also the $\mathrm{Na}^{+}$ions in the outer water layer that have to be reorganized; Lys537 pushes ions towards the Glu residue to enable its penetration through water layers. The distance between Lys535 and the closest $\mathrm{Na}^{+}$is only $3.3 \AA$ because the same ion interacts with the Ala583 carboxyl group; it probably prevents a strong interaction between Lys 535 and the surface itself.
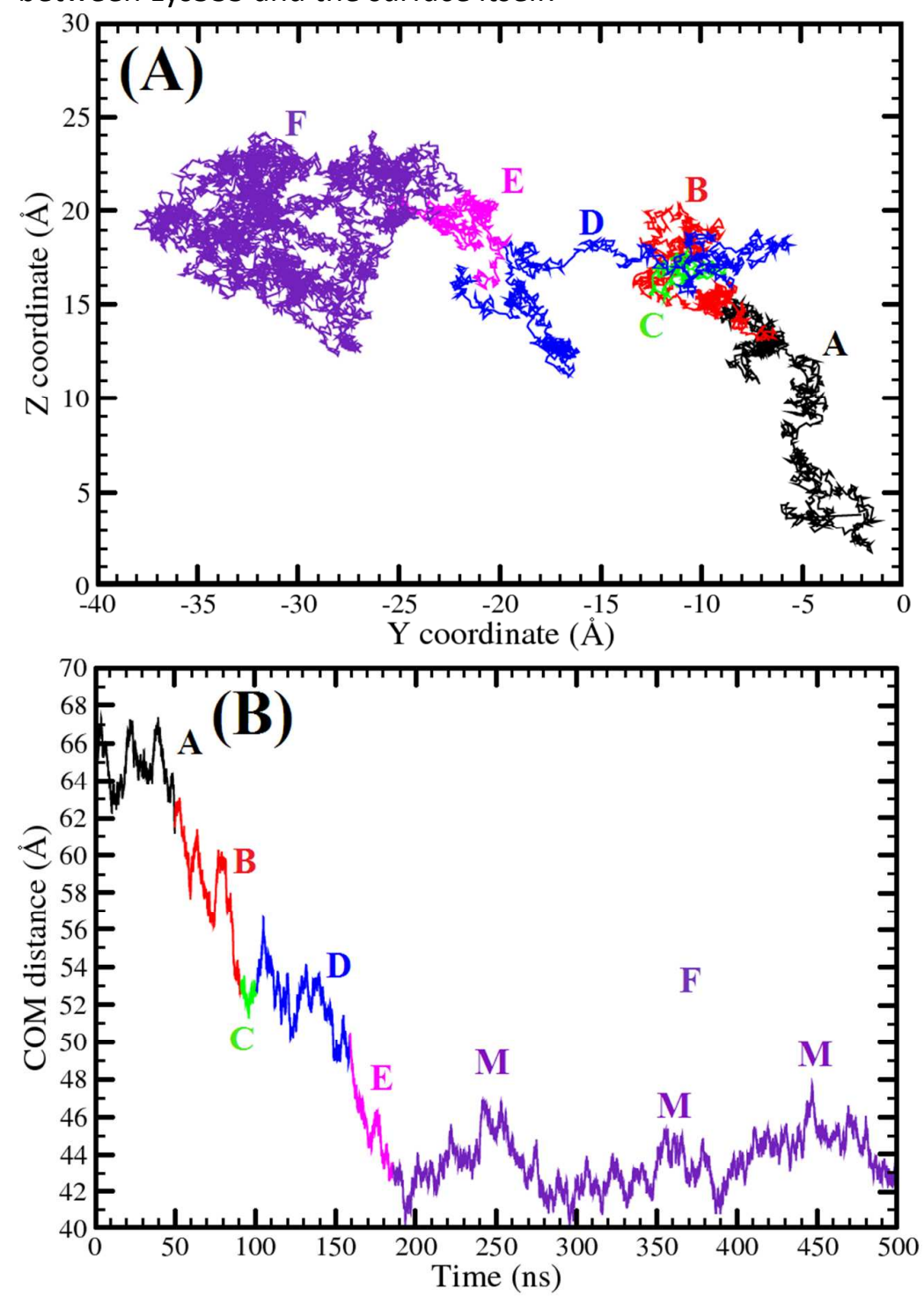

Figure 4. BSA center of mass (COM) diffusion. (A) Plan view of the diffusion across the plane of the surface $(y, z)$. (B) COM distance to the surface ( $x$ coordinate) versus time. Colors: black, red, green, blue, pink and purple indicate stages: $A, B, C, D, E$ and $F(M)$ of the adsorption (annotated).

As Table 2 indicates, at $0.5 \mu$ s (Stage F) the structure we observe has 13 hydrogen bonds between key BSA residues and the outer water layer and $2 \mathrm{H}$-bonds with the inner water layer. According to Kurrat et al the adsorption is strong, and probably irreversible. ${ }^{49}$ Irreversible adorption also agrees with our MP-SPR results below. 
Our extended Stage F trajectory shows that Lys537 can temporarily desorb: instead of penetrating through both water layers and interacting directly with the surface, it moves above the water layers and interacts with the top of the ion layer (Stage M). Note the Lys537 desorption does not initiate full BSA desorption; the BSA remains adsorbed through Glu494, Thr495, Lys535, Thr539, Glu541, GIn542, Thr580 and Ala583, however now protein diffusion across the surface is possible. Once a new, alternative protein location on the surface is found, Lys537 comes back to its adsorbed state with effective penetration through the surface layers. This scenario is repeated, cycling between Stage $F$ and Stage $M$, with the residence time in each stage being 50-80ns for $F$ and 30-40ns for $M$. The adsorbed protein mobility is illustrated in the COM traces across the surface shown in Fig. 4. The adsorption and diffusion process is shown in an accompanying movie (BSA_SiO2.avi) provided in the Supplementary Materials.

Subsequent SMD simulations reveal that the energy required to pull Lys537 away from the surface water layers is around $(0.35 \pm 0.1) \mathrm{eV}$, while the energy required for full desorption (meaning loss of all contacts with the surface itself and the surface water) of this residue is roughly twice as high. We can expect that the energy barrier for full protein desorption (understood as desorption of all residues interacting with the surface) would at least be $>0.7 \mathrm{eV}$. This means that the energy barrier for surface diffusion is sufficiently low to be observable in the ns time-scale of our fully-atomistic MD simulations. These energy barriers explain the negligible desorption observed in MP-SPR below, but also imply a large surface diffusion constant $\left(3 \times 10^{-8} \mathrm{~cm}^{2} / \mathrm{s}\right)$ for individual BSA adsorbed to the surface, something that could be tested in future experimental work.

It is interesting to contrast the repeated surface diffusion observed in Stage $F$ to the behaviour observed in the initial, temporary adsorption Stage $C$. The time moment $92.76 \mathrm{~ns}$ is chosen to represent Stage $C$, and Table 2 lists the residues interacting with the surface at this time in the trajectory. There is only one hydrogen bond created with the surface water, so that according to Kurrat et $a l^{49}$ this stage should not be stable and indeed it is not, as shown by our results. The residues from the final $\alpha$-helix 29 oriented towards the surface are: Lys573, Val569, Glu570, Val576 and Thr580. It is noteworthy that this list is a mixture of positively and negatively charged, as well as hydrophobic and hydrophilic, residues. The positively charged Lys573 forces the migration of $\mathrm{Na}^{+}$ions (towards Glu570) and interacts directly with the surface, while the negatively charged Glu570 interacts with $\mathrm{Na}^{+}$from the ion layer. Thr580 is only slightly hydrophilic while Val is strongly hydrophobic, suggesting that hydrophobic forces also play an important role and help cause the BSA desorption observed at 100.88 ns when Lys573 loses its contact with the surface water layers.

Table 2. Interactions of key $\mathrm{BSA}$ residues with the $\mathrm{SiO}_{2}$ surface, water layers and ions at the initial adsorption Stage C (92.76ns; residues indicated by superscript $C$ ) and the final adsorption Stage $F(500 n s$; residues indicated by superscript $F)$.

\begin{tabular}{|c|c|c|c|c|c|c|}
\hline \multirow[t]{2}{*}{ Residue } & \multirow[t]{2}{*}{ Protein structure } & \multicolumn{2}{|c|}{$\begin{array}{l}\text { Minimal distance to } \\
{[\AA ̊]}\end{array}$} & \multirow[t]{2}{*}{$\begin{array}{l}\text { Interacts } \\
\text { with }\end{array}$} & \multicolumn{2}{|c|}{$\begin{array}{l}\text { Number of } \mathrm{H}- \\
\text { bonds }\end{array}$} \\
\hline & & $\begin{array}{l}\mathrm{SiO}_{2} \\
\text { surface }\end{array}$ & $\begin{array}{l}\mathrm{Na}^{+} \text {ion } \\
\text { layer }\end{array}$ & & $\begin{array}{l}\text { To } \\
\text { water } \\
\text { layer }\end{array}$ & $\begin{array}{l}\text { To } \\
\text { protein }\end{array}$ \\
\hline Val569 & $\alpha$-helix 29 & 6.2 & 4.4 & OWL & 0 & 0 \\
\hline Glu570 & $\alpha$-helix 29 & 8.8 & 4.7 & - & 0 & $\begin{array}{l}1 \\
\text { (Lys573) }\end{array}$ \\
\hline Lys $573^{C}$ & a-helix 29 & 4.2 & 5.8 & IWL & 1 & $\begin{array}{l}1 \\
\text { (Glu570) }\end{array}$ \\
\hline
\end{tabular}




\begin{tabular}{|c|c|c|c|c|c|c|}
\hline Thr580 & a-helix 29 & 8.6 & 5.0 & - & 0 & $\begin{array}{l}1 \\
\text { (Thr580) } \\
1 \\
\text { (Val576) }\end{array}$ \\
\hline Glu494 & $\begin{array}{l}\text { Loop between subdomain } \\
\text { IIIA and IIIB }\end{array}$ & 7.4 & 2.3 & $\begin{array}{l}\mathrm{OWL} \\
\mathrm{Na}^{+}\end{array}$ & 2 & 0 \\
\hline Thr495 ${ }^{\mathrm{F}}$ & $\begin{array}{l}\text { Loop between subdomain } \\
\text { IIIA and IIIB }\end{array}$ & 8.1 & 3.9 & OWL & 2 & 0 \\
\hline Lys $535^{\mathrm{F}}$ & $\begin{array}{l}\text { Loop between } \alpha \text {-helix } 27 \\
\text { and } 28\end{array}$ & 7.1 & 3.5 & OWL & 1 & $\begin{array}{l}1 \\
\text { (Ala583) }\end{array}$ \\
\hline Lys $537^{F}$ & $\begin{array}{l}\text { Loop between } \alpha \text {-helix } 27 \\
\text { and } 28\end{array}$ & 3.5 & 6.8 & $\begin{array}{l}\text { IWL, } \\
\mathrm{SiO}_{2}\end{array}$ & 2 & 0 \\
\hline Thr539F & $\begin{array}{l}\text { Loop between } \alpha \text {-helix } 27 \\
\text { and } 28\end{array}$ & 7.4 & 6.5 & OWL & 1 & 0 \\
\hline Glu541 ${ }^{\mathrm{F}}$ & a-helix 28 & 6.7 & 2.3 & $\begin{array}{l}\mathrm{OWL} \\
\mathrm{Na}^{+}\end{array}$ & 2 & 0 \\
\hline$G \ln 542^{F}$ & $\alpha$-helix 28 & 6.9 & 5.7 & OWL & 2 & 0 \\
\hline Thr $580^{\mathrm{F}}$ & a-helix 29 & 7.1 & 2.3 & OWL & 1 & 0 \\
\hline Ala $583^{\mathrm{F}}$ & a-helix 29 & 7.0 & 2.2 & $\begin{array}{l}\mathrm{OWL} \\
\mathrm{Na}^{+}\end{array}$ & 0 & $\begin{array}{l}1 \\
\text { (Lys535) }\end{array}$ \\
\hline
\end{tabular}

*IWL - Inner Water Layer

OWL - Outer Water Layer

The role of hydrophobicity and charge in the stable adsorbed stage.

A good way to better understand the role of protein charge and hydrophobicity in the adsorption is provided by the maps of the charged and hydrophobic/hydrophilic residues on protein surface facing the silica (Fig. 5). The top three images show the maps from stage $C$, when the BSA temporally adsorbed for almost 10ns, while the bottom images show the adsorption in Stage $F$ (the structure used is that after the full $0.5 \mu \mathrm{s}$ ), which we believe is the long term, stable adsorption stage. The images on the left side show the BSA structure and the residues identified as important for the adsorption. The middle ones show the distribution of charged residues on the protein surface facing the silica, while those on the right side show the distribution of the hydrophilic and hydrophobic residues. All the above are viewed from the bottom, e.g. from the $\mathrm{SiO}_{2}$ surface side. To make the comparison easier the region that contains residues interacting with the surface is circled (note that not all residues from the circle interact with the surface).

In the initial adsorption stage $\mathrm{C}$, the $\mathrm{BSA}$ surface directly facing the $\mathrm{SiO}_{2}$ surface is rather negative; the only positive residue in this area is Lys573. Simultaneously this part does not have a clear hydrophilic or hydrophobic character. The situation is substantially different in the final adsorption stage $\mathrm{F}$, where protein surface facing the silica is more positive (two positive: Lys535 and Lys537 versus three negative: Glu494, Glu541 and Ala583 residues) and, perhaps more importantly, very hydrophilic. In the center of the adsorbing region there is one small hydrophobic area that seems to be well buried. From this we conclude that in the final adsorbed stage $\mathrm{F}$ the part of $\mathrm{BSA}$ interacting with the $\mathrm{SiO}_{2}$ surface is mainly hydrophilic and the charge is better balanced that in stage $C$. The role of the charge distribution within the interaction area seems to be less important than the hydrophobicity map.

Further analysis of Figure 5 leads to observation that stage $C$ is temporary due to its hydrophobicity. At this stage there are numerous hydrophobic residues facing the 
hydrophilic $\mathrm{SiO}_{2}$ surface and surface water layers, and the electrostatic forces are not strong enough to overcome the energy barriers produced by this hydrophobicity. This is the likely reason for the desorption from this state after $\sim 10 \mathrm{~ns}$. The desorbed protein changes its orientation with respect to the surface and subsequently adsorbs using a much more hydrophilic region. The new adsorption region comprises a mixture of positive and negative residues, allowing the positive residues to interact with the surface while providing negatively charged scavengers for displaced $\mathrm{Na}^{+}$ions.
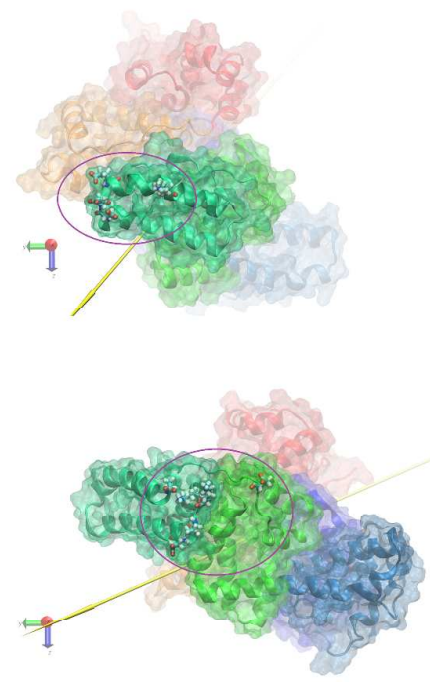

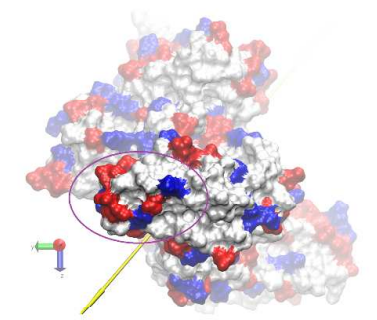

Initial adsorbed stage (stage $\mathrm{C}$ )

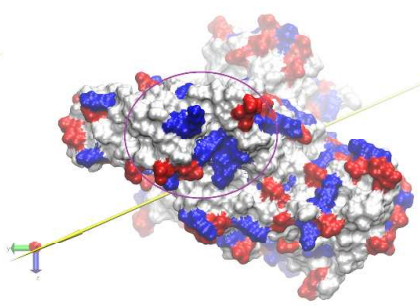

Final adsorbed stage (stage $F$ )
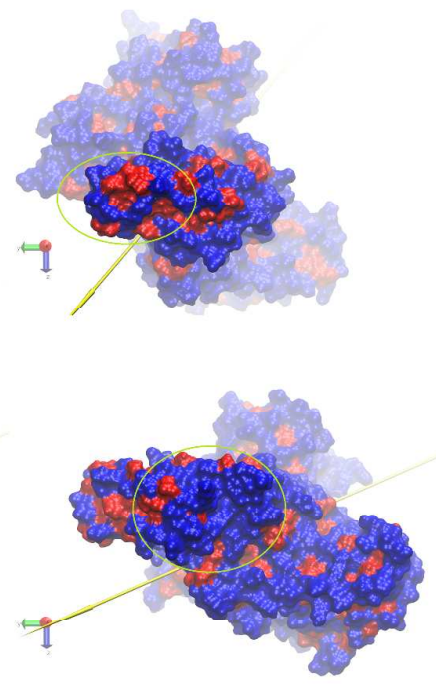

Figure 5. BSA structure (left) compared with its surface charge (middle) and hydrophobicity (right) maps. The color scheme is the same as in Fig. 1. The top pictures show the initial, temporary adsorbed stage $C$ while the bottom ones show the final adsorbed stage $F$. The protein is viewed from the $\mathrm{SiO}_{2}$ surface side but the $\mathrm{SiO}_{2}$ atoms are not shown for the clarity. VMD's deep cueing option is used to indicate the distance of each protein part to the surface. The region containing the most important residues for each adsorption stage is circled, nevertheless not all residues in the circle should be considered as equally important for the adsorption.

\section{Structural changes}

Contrary to $\mathrm{BSA}$ adsorption on graphite, ${ }^{23}$ on $\mathrm{SiO}_{2}$ the $\mathrm{BSA}$ does not unfold. The root mean square distance between initial and final (after $0.5 \mu \mathrm{s}$ ) structures is $3.11 \AA$, a value surprisingly low for such a large and flexible protein. It suggests that the $\mathrm{BSA}$ adsorption on $\mathrm{SiO}_{2}$ does not require any substantial changes that might be detected in experiments to adsorb. As shown in Fig. 6 , the BSA structural elements are maintained after adsorption, and significant $\alpha$-helix unfolding or domain reorganization is not observed. Indeed, the RMSD plotted versus time (data not shown) indicates that the structure is stable during the entire adsorption trajectory. 


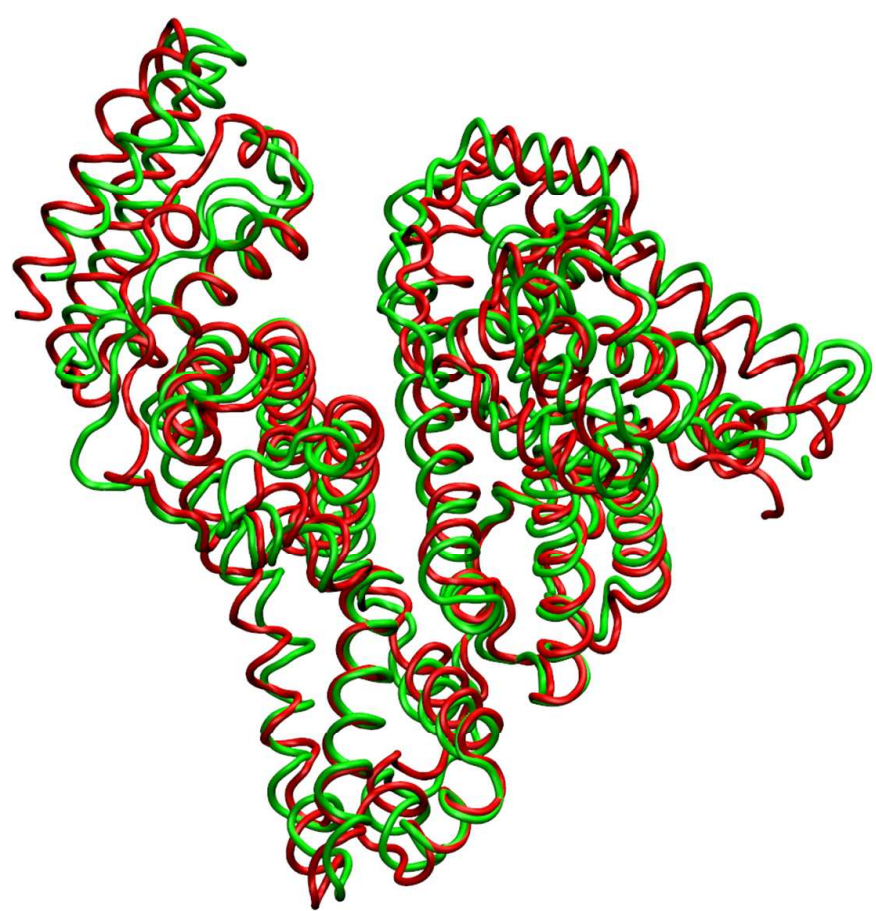

Figure 6. BSA structure overlap. The initial structure before adsorption is shown by the red ribbon, while final one (after the $0.5 \mu$ s trajectory) is shown by the green one.

\section{EXPERIMENTAL RESULTS}

\section{DLS}

A quantitative interpretation of the BSA adsorption experiments requires detailed physicochemical characteristics of the bulk protein. One of the most important parameters is the bulk solution diffusion coefficient, since the mobility of the protein in solution yields its hydrodynamic radius, which in turn characterizes the aggregation (if any) of the protein or its monomeric form (native or unfolded)..$^{18,36-37}$

Using Dynamic Light Scattering measurements, we obtain the BSA diffusion coefficient (D) dependence on bulk concentration (within the range of 500-4000 ppm).The diffusion coefficient of BSA is independent of its bulk concentration. We obtain average values of $D=6.0 \times 10^{-7} \mathrm{~cm}^{2} \mathrm{~s}^{-1}$ and $D=5.6 \times 10^{-7} \mathrm{~cm}^{2} \mathrm{~s}^{-1}$ for ionic strength $1 \times 10^{-2} \mathrm{M}$ and $1 \times 10^{-3} \mathrm{M} \mathrm{NaCl}$, respectively (at $\mathrm{pH}$ 6.3). Since our $\mathrm{MD}$ simulations were performed at $1 \times 10^{-2} \mathrm{M}$, and the insensitivity of the BSA diffusion coefficient to ionic strength, the following discussion focuses on the results obtained for $1 \times 10^{-2} \mathrm{M}$ ionic strength.

Using these diffusion coefficient values, the Stokes hydrodynamic radius $R_{H}$ of the BSA can be calculated from Stokes-Einstein equation. The average $R_{H}$ value is $4.1 \mathrm{~nm}$ for $\mathrm{pH}$ 4-9 with $\mathrm{I}=1 \times 10^{-2} \mathrm{M} \mathrm{NaCl}$, and seems to be independent of $\mathrm{pH}$ across this range. At $\mathrm{pH}<4$ and $\mathrm{pH}>9$, the $R_{H}$ values are slightly larger as shown in Fig. 7. This indicates that the protein is monomeric and keeps its compact conformation observed at physiological $\mathrm{pH}$, except at extreme $\mathrm{pH}$ where it undergoes unfolding. This behaviour agrees with that reported in the literature. ${ }^{12,50-51}$ 


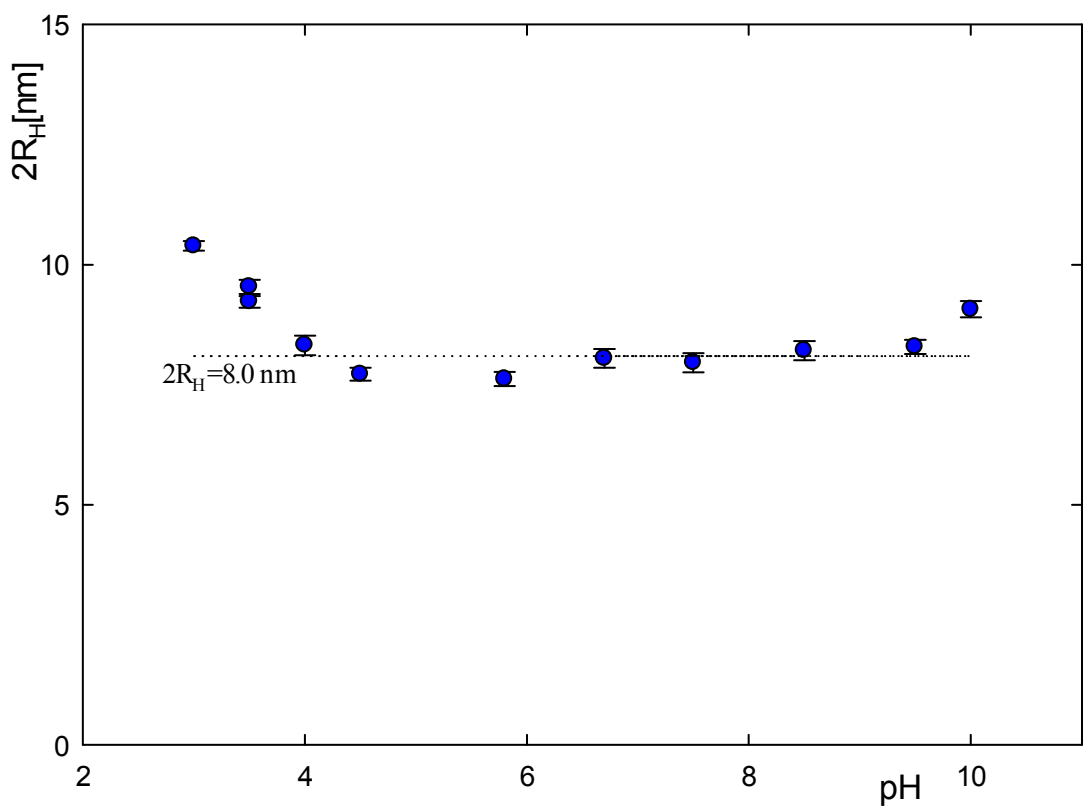

Figure 7. The dependence of $\mathrm{BSA}$ hydrodynamic diameter $(2 \mathrm{RH})$ on $\mathrm{pH}$ determined from

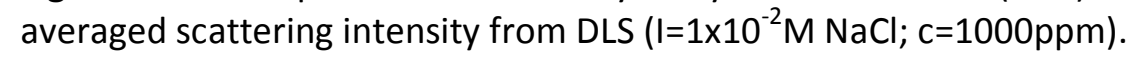

\section{Zeta potential}

The electrostatic interactions between proteins and model surfaces play a significant role in the adsorption process. ${ }^{18,30,52-53}$ Indeed, as we have shown above, the MD simulations indicate that electrostatics plays a major role in steering the adsorption pathway of the BSA onto the silica surface at $\mathrm{pH} 7$. To provide a better understanding of the protein adsorption to the silica surface we separately measured the zeta potential of the BSA molecules and the silica surface. Figure 8 presents the results using the same axes to aid discussion.

The zeta potential of the BSA was estimated by the electrophoretic mobility measurement and calculated using the Henry equation (for details see Supplementary materials). The zeta potential of the BSA was determined as a function of $\mathrm{pH}(2.5-10.5)$ at different $\mathrm{NaCl}$ ionic strengths $\left(I=1 \times 10^{-3} \mathrm{M} ; \mathrm{I}=5 \times 10^{-3} \mathrm{M} ; \mathrm{I}=1 \times 10^{-2} \mathrm{M} ; \mathrm{I}=0.15 \mathrm{M}\right)$ (Fig. 9), while the zeta potential of the silica surface was estimated as a function of $\mathrm{pH}(3.5-10.0)$ at $\mathrm{I}=1 \times 10^{-2} \mathrm{M}$ using the Surface Zeta Potential Cell. ${ }^{18}$

The isoelectric point (IEP) of BSA was determined to be $\mathrm{pH} 5.1$ (the zero value of its zeta potential). For $\mathrm{pH}$ lower than 5.1 the BSA net charge is positive and for $\mathrm{pH}$ values above the IEP it is negative. Over this entire $\mathrm{pH}$ range the silica surface is negatively charged. These results suggest that BSA should readily adsorb on silica below $\mathrm{pH} 5.1$, because of the favorable electrostatic interactions; the BSA molecules and silica surface are oppositely charged. Above the BSA isoelectric point, both the BSA and the silica zeta potentials are negative, which might be thought to prevent the BSA adsorption due to electrostatic repulsion. Surprisingly, the MD simulation, MP-SPR and contact angle studies all show that $\mathrm{BSA}$ adsorbed on silica surface at a whole range of $\mathrm{pH}$ from 3.0 to 9.0. This BSA adsorption behaviour is explained above by the numerous positively charged Arg and Lys as well as negatively charged Asp and Glu residues in the protein, yielding an inhomogeneous charge distribution across the protein surface that couples with the ionic screening layers above the 
silica. We have also seen above that electrostatics alone does not govern the adsorption behaviour; hydrophobicity plays an important role too.

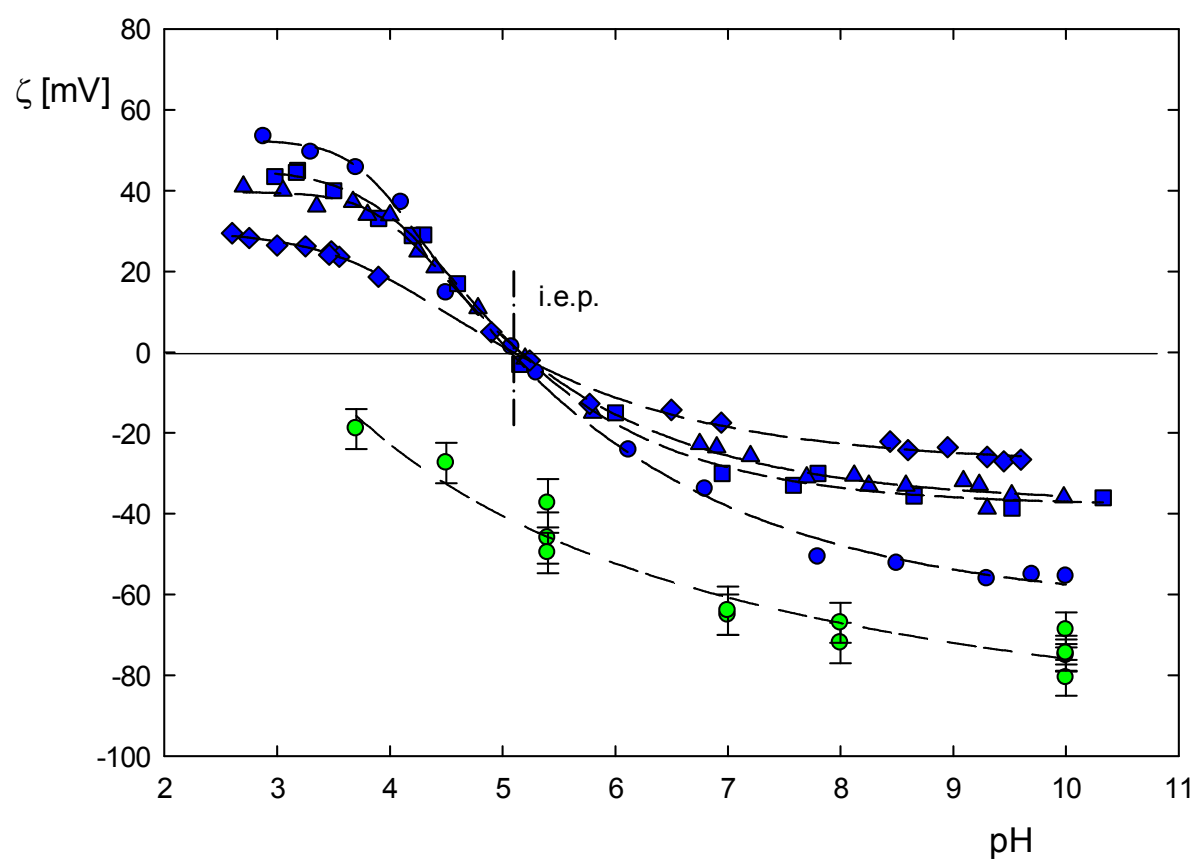

Figure 8. The dependence of the silica zeta potential $\zeta$ (green points) and BSA molecule (blue points) on $\mathrm{pH}$ as determined by the surface potential measurments at ionic strength $\mathrm{I}=1 \times 10^{-}$ ${ }^{2} \mathrm{M}$. ${ }^{18}$ The blue points denote experimental results obtained from the electrophoretic mobility measurement: $\bullet \mathrm{I}=1 \times 10^{-3} \mathrm{M} ; \boldsymbol{\nabla} \mathrm{I}=5 \times 10^{-3} \mathrm{M} ; \boldsymbol{\Delta} \mathrm{I}=1 \times 10^{-2} \mathrm{M} ; \bullet \mathrm{I}=0.15 \mathrm{M}$.

\section{MP-SPR measurement of adsorbed mass and monolayer formation}

The MP-SPR technique was used to measure the dependence on $\mathrm{pH}$ of the BSA adsorption mass on the silica surface (see Fig. 9). This optical method measures the 'dry' mass of the adsorbed protein. BSA was adsorbed in a pH range from 3.0 to 9.0 and ionic strength $I=1 \times 10^{-2} \mathrm{M} \mathrm{NaCl}$. The surface density of the BSA adsorbed to silica changes from $6 \mathrm{ng} / \mathrm{cm}^{2}$ at $\mathrm{pH} 3.0$ to $51 \mathrm{ng} / \mathrm{cm}^{2}$ at $\mathrm{pH}$ 9.0. The highest value of adsorbed mass appears at $\mathrm{pH} 5.0-5.5$ and is equal $128 \mathrm{ng} / \mathrm{cm}^{2}$. These results are in very good agreement with the protein isoelectric measured at $\mathrm{pH} 5.1$. $^{36,38}$

Furthermore, the difference between surface-adsorbed mass while exposed to the protein solution and that remaining after washing the surface with buffer provides information about the reversibility of the adsorption. In all cases, the desorption upon washing is less than $5 \%$ of the total protein adsorbed mass, which indicates good irreversibility of the process. It suggests a strong $\mathrm{BSA}$ interaction with $\mathrm{SiO}_{2}$, even when the BSA is negatively charged and adsorbing to a negatively charged surface. This agrees well with our MD simulations results, which shows the BSA adsorption at $\mathrm{pH} 7$ is irreversible on the simulation timescale. Our SMD results also show that the energy required for desorption is such that it should not occur even on the experimental timescale of hours, just as we observe. 


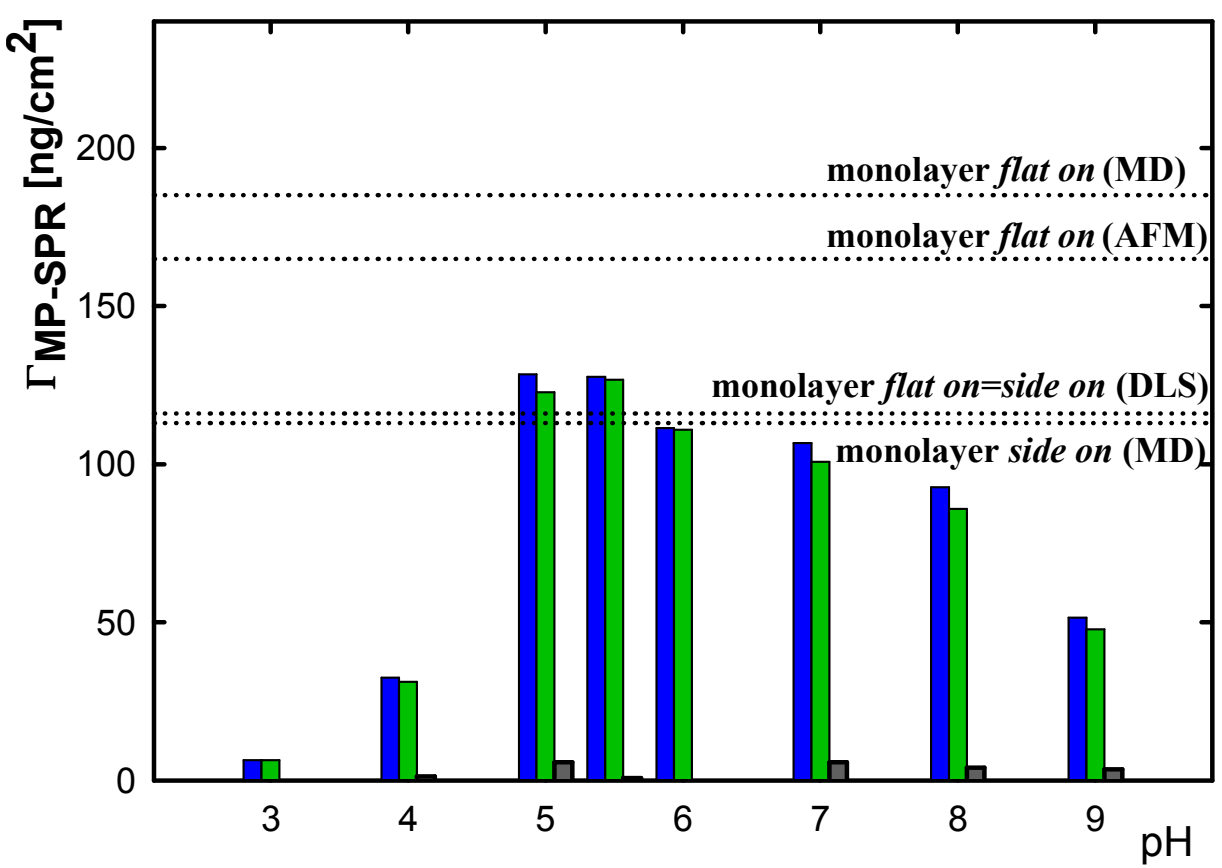

Figure 9. BSA adsorbed mass per unit area at the silica surface using the MP-SPR method (BSA concentration $5 \mathrm{ppm}, \mathrm{NaCl} I=1 \times 10^{-2} \mathrm{M} \mathrm{NaCl}$, and $\mathrm{pH}$ range $3.0-9.0$ ).

The anticipated monolayer adsorbed mass can be calculated using the BSA molecular dimensions obtain by various techniques: $A F M,{ }^{18} \mathrm{DLS}^{36,38}$ and MD (this work). The amount of adsorbed protein measured by MP-SPR can be directly compared with the calculations presented in Tab.3, as indicated by the dotted lines in Fig. 8. According to the Random Sequential Adsorption (RSA) model, the maximum surface coverage $\Theta^{\text {RSA }}$ is equal to $0.547 . .^{54}$ The estimated surface mass density of a BSA monolayer, using the molecular size estimated by $A F M,{ }^{18}$ is $165 \mathrm{ng} / \mathrm{cm}^{2}$ and $220 \mathrm{ng} / \mathrm{cm}^{2}$ for "flat-on" and "side-on" orientation, respectively; flat-on assumes the BSA is adsorbed with its triangular face facing the surface, whereas sideon assumes that its stands on a rectangular edge. Using these figures, our experimental maximum surface coverage, $\Theta^{\mathrm{MP}-\mathrm{SPR}}$ is 0.424 (flat-on) and 0.317 (side-on). Therefore, the protein surface coverage is limited to a maximum of $78 \%$ (flat-on) and $58 \%$ (side-on) of a complete monolayer on the hydrophilic silica surface. This may simply demonstrate that for all $\mathrm{pH}$ levels, the surface is never fully covered with BSA, even when BSA molecule has a minimum net charge. However, we note that estimating molecular dimensions using AFM is challenging due to the curvature effects of the AFM tip, so that the results might better be interpreted using the MD simulation results presented above.

Using on the MD measurements for the cross-sectional footprint area of BSA adsorbed flat-on and side-on, the monolayer capacity is $185 \mathrm{ng} / \mathrm{cm}^{2}$ and $131 \mathrm{ng} / \mathrm{cm}^{2}$, respectively. In this case, experimental maximum surface coverage, $\Theta^{\mathrm{MP}-\mathrm{SPR}}$ is 0.378 (flat-on) and 0.534 (side-on), which indicates the protein surface coverage limited to a maximum of $69 \%$ (flat-on) and $98 \%$ (side-on) of a complete RSA monolayer. Furthermore, the MD adsorption simulation studies (at $\mathrm{pH} 7$ ) suggest that side-on is the preferred orientation of the $\mathrm{BSA}$ on $\mathrm{SiO}_{2}$ surface, which was also shown by $\mathrm{Su}$ et al using neutron reflection. ${ }^{55}$ Therefore in the $\mathrm{pH}$ range 5.0-6.0 the observed adsorbed mass density is consistent with a 
Table 3. Data used to estimate the adsorbed monolayer mass density. The BSA size reports three triangular side lengths and the 'thickness' of the heart-shaped BSA. $A_{p}\left[\mathrm{~nm}^{2}\right]$ is the estimated footprint area of a single BSA adsorbed at the surface in the "flat-on" and "sideon" orientations. For the DLS data, the BSA is assumed to be a sphere with the given radius.

\begin{tabular}{|c|c|c|c|c|c|}
\hline $\begin{array}{l}\text { Method } \\
\text { BSA size [nm] }\end{array}$ & \multicolumn{2}{|c|}{$\begin{array}{c}\mathrm{AFM}^{18} \\
(9.2 \times 9.2 \times 9.2 \times 3.0)\end{array}$} & $\begin{array}{c}\mathrm{DLS} S^{36} \\
R_{H}=4.1\end{array}$ & \multicolumn{2}{|c|}{$\begin{array}{c}M D \\
(9.1 \times 8.5 \times 8.0 \times 5.4)\end{array}$} \\
\hline Orientation & flat on & side on & $\begin{array}{l}\text { flat on }= \\
\text { side on }\end{array}$ & flat on & side on \\
\hline$A_{p}\left[n^{2}\right]$ & 36.7 & 27.6 & 52.8 & 32.7 & 46.1 \\
\hline$\Theta^{\mathrm{RSA}}$ & \multicolumn{5}{|c|}{0.547} \\
\hline$\Gamma^{\mathrm{RSA}}\left[\mathrm{ng} \cdot \mathrm{cm}^{-2}\right]$ & 165 & 220 & 115 & 185 & 131 \\
\hline
\end{tabular}

\section{Contact Angle}

Contact angle gives some insight into the wettability characteristics of the silica surface. Bare silica is considered to be hydrophilic and has a contact angle of $18^{\circ}$. It can be seen from Fig. 10 that the tendency is to increase the contact angle with the presence of adsorbed BSA. The maximum was obtained at $\mathrm{pH}$ 5.0-5.5, near the protein isoelectric point, at both the studied adsorption times ( $5 \mathrm{~min}$ and $150 \mathrm{~min}$ ). After $5 \mathrm{~min}$ of BSA adsorption on $\mathrm{SiO}_{2}$ the contact angle was equal $30^{\circ}$ at $\mathrm{pH}$ 5.5. At the same $\mathrm{pH}$ but with the longer adsorption time of $150 \mathrm{~min}$, the contact angle increased to $50^{\circ}$. In our previous work ${ }^{18}$ we estimated that by $150 \mathrm{~min}$ of BSA adsorption (with solution concentration of $5 \mathrm{ppm}$ ) the contact angle reaches a plateau value for all $\mathrm{pH}$, indicating that the surface is saturated and the adsorption is complete.

At $\mathrm{pH}>5.5$, the contact angle decreases, with the angle at $\mathrm{pH} 9\left(\sim 27^{\circ}\right)$ lower than at $\mathrm{pH} 7\left(\sim 32^{\circ}\right)$. This can be understood in terms of the MP-SPR adsorbed mass density shown above in Fig. 10, which indicates a monolayer formation around the IEP and decreasing coverage as the $\mathrm{pH}$ increases. The MD simulations indicate that the adsorbed BSA exposes hydrophilic parts of its surface towards the silica, so that more hydrophobic parts of the BSA are left exposed to the solvent. This is illustrated in the hydrophobicity map of the adsorbed BSA viewed from above the surface (Fig. 11). Therefore the hydrophobicity of the surface increases with BSA coverage, provided the protein orientation remains that found in the simulations. These are performed at $\mathrm{pH} 7$ with negatively protein and surface, and provide a rational basis for understanding the adsorption at $\mathrm{pH}$ above the IEP and up to $\mathrm{pH} 9$, after 
which protein conformational changes take place (see Fig. 8 above for the hydrodynamic radius). ${ }^{38}$

Below the protein's IEP (pH5.1), the charge on the protein is positive and opposite to that of the silica surface. In this regime, the orientation of the protein on the surface is unknown from the MD simulations, but the MP-SPR again indicates a decreasing surface coverage and therefore a decrease of the contact angle towards that of the bare surface.

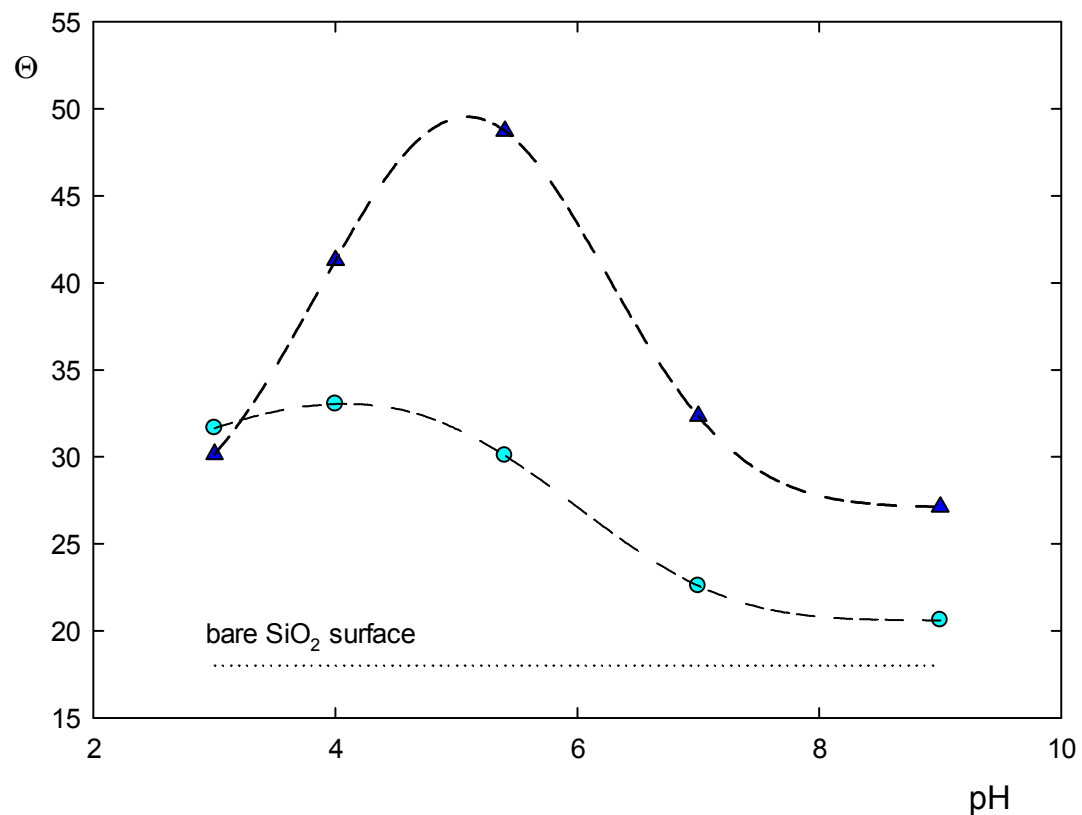

Figure 10. Contact angle measured for bare and $\mathrm{BSA}$-adsorbed $\mathrm{SiO}_{2}$ surface at $\mathrm{pH}$ range 3 to 9 (BSA concentration $5 \mathrm{ppm} ; \mathrm{I}=1 \times 10^{-2} \mathrm{M} \mathrm{NaCl}$ ). Cyan circles: adsorption time $5 \mathrm{~min}$; navy triangles: adsorption time $150 \mathrm{~min}$; the short-short lines shows the trend-line fit of experimental points, dotted line: contact angle for bare silica surface.

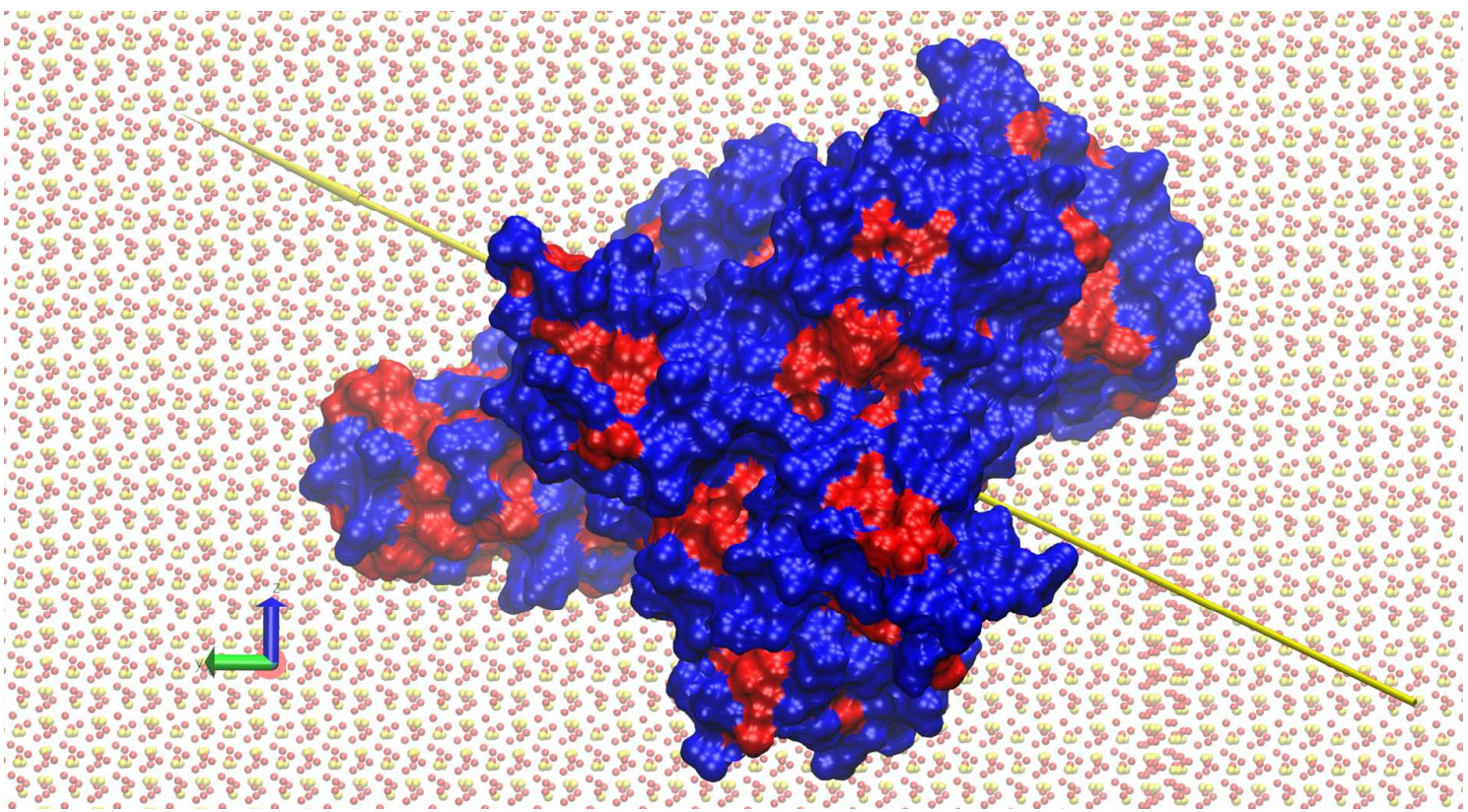

Figure 11. The hydrophobicity map of the adsorbed BSA viewed from above the surface. The adsorption structure and color scheme are the same as used in Fig. 5 stage F. 


\section{Conclusions}

The simulation and experimental results presented here combine to give a comprehensive understanding of the adsorption of BSA onto a silica surface and how $\mathrm{pH}$ affects the process. The atomistic MD simulations provide a detailed description of the adsorption mechanism at pH7 where both the silica surface and the BSA are negatively charged. The picture that emerges for the balance between long-range electrostatic steering affects coupled to the ionic screening of the silica, and the short-range hydrophobic forces, enables a broader interpretation of experiments across the $\mathrm{pH}$ range 3-9.

We have found that BSA is monomeric in solution for concentrations $500-4000 \mathrm{ppm}$, keeping its compact conformation and only starting to unfold for $\mathrm{pH}<4$ and $\mathrm{pH}>9$. Thus the MD model for monomeric adsorption at $\mathrm{pH} 7$ is experimentally relevant above the IEP (observed here to be pH5.1) where both the BSA and the silica are negatively charged. The simulations show how the adsorption occurs despite the electrostatic forces, aided by the effects of screening ions, the surface water layers and hydrophobic forces. Furthermore, the BSA is ultimately found to be strongly adsorbed, with $8 \mathrm{H}$-bonds formed between it and the surface water layers, so that it will not be readily desorbed. ${ }^{48}$ This agrees well with our experimental observations for the adsorbed surface mass density using MP-SPR.

Despite the irreversible nature of the adsorption, the simulations suggest that he BSA will diffuse across the silica surface, promoting the formation of protein islands and ultimately complete monolayers. This again agrees with the experimental results for adsorbed mass density, with monolayer formation indicated at $\mathrm{pH} 5-\mathrm{pH} 6$, and diminishing surface coverage at higher $\mathrm{pH}$ as the magnitude of the negative charge density increases on both the silica and the BSA. We also correlate this behaviour with the observed variation in the surface contact angle, which is maximum at $\mathrm{pH} 5$ and diminishes as the surface coverage decreases. The high contact angle for a coated surface is explained in terms of the orientation of the adsorbed protein, which exposes more hydrophilic parts of the BSA surface to the substrate and therefore leaves less hydrophilic regions exposed to solution.

From the above summary, it is clear that the simulations provide crucial molecularscale insight to the experimental observations, and that in combination the methods can paint a comprehensive picture for the adsorption of proteins and the formation of protein films. Of particular note is the simulation finding that the adsorbed protein remains largely intact, so that its functionality may well be preserved. This presents new opportunities to exploit functionalized films for future biotechnological applications.

\section{Acknowledgements}

The presented work was supported by Grant NCN OPUS24 2012/07/B/ST5/00767. MD results were obtained using the EPSRC funded ARCHIE-WeSt High Performance Computer (www.archie-west.ac.uk); EPSRC grant no. EP/K000586/1.

\section{Supporting Information}

Figure illustrating dependence of the $\mathrm{pH}$ of BSA solution on concentration together with movie showing the $0.5 \mu$ s adsorption trajectory of BSA at the silica surface. 


\section{References}

(1) Huebsch, N.; Mooney, D. J. Inspiration and Application in the Evolution of Biomaterials. Nature 2009, 462, 426-432.

(2) Pastor, E.; Matveeva, E.; Valle-Gallego, A.; Goycoolea, F. M; Garcia-Fuentes, M. Protein Delivery Based on Uncoated and Chitosan-Coated Mesoporous Silicon Microparticles. Colloids Surf. B 2011, 88, 601-609.

(3) Luckarift, H. R.; Spain, J. C.; Naik, R. R.; Stone, M. O. Enzyme Immobilization in a Biomimetic Silica Support. Nat. Biotechnol. 2004, 22, 211-213.

(4) Carlsson, N.; Gustafsson, H.; Thorn, Ch.; Olsson, L.; Holmberg, K.; Akerman, B. Enzymes Immobilized in Mesoporous Silica: A Physical-Chemical Perspective. Adv. Colloid Interface Sci. 2014, 205, 339-360.

(5) Majorek, K. A.; Porebski, P. J.; Dayal, A.; Zimmerman, M. D.; Jablonska, K.; Stewart, A. J.; Chruszcz, M.; Minor, W. Structural and Immunologic Characterization of Bovine, Horse, and Rabbit Serum Albumins. Mol. Immunol. 2012, 52, 174-182.

(6) Kondo, A.; Murakami, F.; Higashitani, K. Circular Dichroism Studies on Conformational Changes in Protein Molecules Upon Adsorption on Ultrafine Polystyrene Particles. Biotechnol. Bioeng. 1992, 40, 889-894.

(7) Bujacz, A.; Zielinski, K.; Sekula, B. Structural Studies of Bovine, Equine, and Leporine Serum Albumin Complex With Naproxen. Prot. Struct. Funct. Bioinformatics 2014, 82, 2199-2208.

(8) Abdelhameed, A. S. Insight Into the Interaction Between the HIV-1 Integrase Inhibitor Elvitegravir and Bovine Serum Albumin: A Spectroscopic Study. J. Spectroscopy, 2015, 435674.

(9) Rub, M. A.; Khan, J. M.; Asiri, A. M.; Khan, R. H; Ud-Din, K. Study of the Interaction Between Amphiphilic Drug and Bovine Serum Albumin: A Thermodynamic and Spectroscopic Description. J. Luminescence, 2014, 155, 39-46.

(10) Hamilton, J. A. NMR Reveals Molecular Interactions and Dynamics of Fatty Acid Binding to Albumin. Biochim. Biophys. Acta 2013, 1830, 5418-5426.

(11) Liu, S.; Guo, Ch.; Guo, Y.; Yu, H.; Greenaway, F.; Sun, M. Z. Comparative Binding Affinities of Flavonoid Phytochemicals With Bovine Serum Albumin. Iran. J. Pharm. Res. 2014, 13, 1019-1028.

(12) Russell, B. A.; Kubiak-Ossowska, K.; Mulheran, P. A.; Birch, D. J. S.; Chen, Y. Locating the Nucleation Sites For Protein Encapsulated Gold Nanoclusters: A Molecular Dynamics and Fluorescence Study. Phys. Chem. Chem. Phys. 2015, 17, 21935-21941.

(13) Humphrey, W.; Dalke, A.; Schulten, K. VMD: Visual Molecular Dynamics. J. Mol. Graphics 1996, 14, 33-38.

(14) Kyte, J.; Doolittle, R. F. A Simple Method for Displaying the Hydropathic Character of a Protein. J. Mol. Biol. 1982, 157, 105-132.

(15) Benavidez, T. E.; Torrente, D.; Marucho, M.; Garcia, C. D. Adsorption of Soft and Hard Proteins Onto OTCEs Under the Influence of an External Electric Field. Langmuir 2015, 31, 2455-2462.

(16) Nooney, R. I.; White, A.; O'Mahony, Ch.; O'Connell, C.; Kelleher, S. M.; Daniels, S.; McDonagh, C. Investigating the Colloidal Stability of Fluorescent Silica Nanoparticles Under Isotonic Conditions For Biomedical Applications. J. Coll. Int. Sci. 2015, 456, 50-58.

(17) McUmber, A. C.; Randolph, T. W.; Schwartz, D. K. Electrostatic Interations Influence Protein Adsorption (but Not Desorption) at the Silica-Aqueous Interface. J. Phys. Chem. Lett. 2015, 6, 2583-2587. 
(18) Jachimska, B.; Tokarczyk, K.; Łapczyńska, M.; Puciul-Malinowska, A. Zapotoczny, Sz. Structure of Bovine Serum Albumin Adsorbed on Silica Investigated by Quartz Crystal Microbalance. Col. Surf. A 2016, 489, 163-172.

(19) Szewczuk-Karpisz, K.; Wisniewska, M. Investigation of Removal Possibilities of Chromium(III) Oxide from Water Solution in the Presence of Albumins. Int. J. Environ. Sci. Technol. 2015, 12, 2947-2956.

(20) Szewczuk-Karpisz, K; Wisniewska, M.; Mysliwiec, D. Albumin Adsorption Influence on the stability of the Mesoporous Zirconia Suspension. J. Indust. Eng. Chem. 2015, 32, 113-119.

(21) Jana, S.; Ghosh, S.; Dalapati, S.; Guchhait, N. Exploring Structural Change of Protein Bovine Serum Albumin by External Perturbation Using Extrinsic Fluorescence Probe: Spectroscopic Measurement, Molecular Docking and Molecular Dynamics Simulation. Photochem. Photobiol. Sci. 2012, 11, 323-332.

(22) Niu, X.; Gao, X.; Wang, H.; Wang, X.; Wang, S. Insight Into the Dynamic Interaction Between Different Flavonoids and Bovine Serum Albumin Using Molecular Dynamics Simulations and Free Energy Calculations. J. Mol Model. 2013, 19, 1039-1047.

(23) Mucksch, Ch.; Urbassek, H. M. Molecular Dynamics Simulation of Free and Forced BSA Adsorption on a Hydrophobic Graphite Surface. Langmuir 2011, 27, 12938-12943.

(24) Gu, Z.; Yang, Z.; Chong, Y.; Ge, C.; Weber, J. K.; Bell, D. R.; Zhou, R. Surface Curvature Relation to Protein Adsorption For Carbon-Based Nanomaterials. Sci. Rep. 2015, 5, 10886.

(25) Delgado-Magnero, K. H.; Valiente, P. A.; Ruiz-Pena, M.; Perez-Gramatges, A.; Pons, T. Unravelling the Binding Mechanism of Polyoxyethylene Sorbitan Esters With Bovine Serum Albumin: A Novel Theoretical Model Based on Molecular Dynamics Simulations. Coll. Surf. Biointerfaces 2015, 116, 720-726.

(26) Kubiak-Ossowska, K.; Jachimska, B.; Mulheran, P. A. How Negatively Charged Proteins Adsorb to Negatively Charged Surfaces: A Molecular Dynamics Study of BSA Adsorption on Silica. J. Phys. Chem. B 2016, 120, 10463-10468.

(27) Phillips, J. C. Braun, R.; Wang, W.; Gumbart, J.; Tajkhorshid, E.; Villa, E.; Chipot, Ch.; Skeel, R. D.; Kale, L.; Schulten, K. Scalable Molecular Dynamics With NAMD. J. Comput. Chem. 2005, 26, 1781-1802.

(28) Kubiak-Ossowska, K.; Burley, G.; Patwardhan, S. V.; Mulheran, P. A. Spontaneous Membrane-Translocating Peptide Adsorption at Silica Surfaces: A Molecular Dynamics Study. J. Phys. Chem. B 2013, 117, 14666-14675.

(29) Kubiak-Ossowska, K.; Mulheran, P. A.; Nowak, W. Fibronectin Module FN ${ }^{\text {III } 9}$ Adsorption and Contrasting Solid Model Surfaces Studied by Atomistic Molecular Dynamics. J. Phys. Chem. B 2014, 118, 9900-9908.

(30) Kubiak-Ossowska, K.; Cwieka, M.; Kaczynska, A.; Jachimska, B.; Mulheran, P. A. Lysozyme Adsorption and a Silica Surface Using Simulation and Experiment: Effects of pH on Protein Layer Structure. Phys. Chem. Chem. Phys. 2015, 17, 24070-24077.

(31) Rezwan, K.; Meier, L. P.; Gauckler, L. J. Lysozyme and Bovine Serum Albumin Adsorption on Uncoated Silica and AlOOH-Coated Silica Particles: The Influence of Positively and Negatively Charged Oxide Surface Coatings. Biomaterials 2005, 26, 4351-4357.

(32) Mathé, Ch.; Devineau, S.; Aude, J.-Ch.; Lagniel, G.; Chédin, S.; Legros, V.; Mathon, M.-H.; Renault, J.-P.; Pin, S.; Boulard, Y.; Labarre, J. Structural Determinants for Protein Adsorption/Non-Adsorption to Silica Surface. PLOS ONE 2013, 8, e81346. 
(33) Wisniewska, M.; Szewczuk-Karpisz, K.; Sternik, D. Adsorption and Thermal Propertied of The Bovine Serum Albumin-Silicon Dioxide System. J. Therm. Anal. Calorim. 2015, 120, 1355-1364.

(34) Essmann, U.; Perera, L.; Berkowitz, M. L.; Darden, T.; Lee, H.; Pedersen, L. A Smooth Particle Mesh Ewald Method. J. Chem. Phys. 1995, 103, 8577- 8593.

(35) Kubiak-Ossowska, K.; Mulheran, P. A. Protein Diffusion and Long-Term Adsorption States at Charged Solid Surfaces. Langmuir 2012, 28, 15577-15585.

(36) Jachimska, B.; Wasilewska, M.; Adamczyk, Z. Characterization of Globular Protein Solutions by Dynamic Light Scattering, Electrophoretic Mobility, and Viscosity Measurements. Langmuir 2008, 24, 6866-6872.

(37) Jachimska, B. Physicochemical characterization of anisotropic molecules (polyelectrolytes and proteins) in bulk solutions, Colloids in Biotechnology, Surfactant Sciences, Vol.152, CRC Press: 2010.

(38) Jachimska, B.; Pajor, A. Physico-Chemical Characterization of Bovine Serum Albumin in Solution and as Deposited on Surfaces. Bioelectrochemistry 2012, 87, 136146.

(39) Larsericsdotter, H.; Oscarsson, S.; Bujis, J. Thermodynamic Analysis of Lysozyme Adsorbed to Silica. J. Colloid Interface Sci. 2004, 276, 261-268.

(40) Kubiak, K.; Mulheran, P. A. Molecular Dynamics Simulations of Hen Egg White Lysozyme Adsorption at a Charged Solid Surface. J. Phys. Chem. B 2009, 113, 12189121200.

(41) Kubiak-Ossowska, K.; Mulheran, P. A. What Governs Protein Adsorption and Immobilization at a Charged Solid Surface? Langmuir 2010, 26, 7690-7694.

(42) Kubiak-Ossowska, K.; Mulheran, P. A. Mechanism of Hen Egg White Lysozyme Adsorption on a Charged Solid Surface. Langmuir 2010, 26, 15954-15965.

(43) Borders, C. L.; Broadwater, A.; Bekeny, P. A.; Salmon, J. E.; Lee, A. S.; Eldridge, A. M.; Pett, V. B. A Structural Role for Arginine in Proteins: Multiple Hydrogen Bonds to Backbone Carbonyl Oxygens. Protein Sci. 1994, 3, 541-548.

(44) Heinz, H.; Farmer, B. L.; Pandey, R. B.; Slocik, J. M.; Patnaik, S. S.; Pacher, R.; Naik, R. R. Nature of Molecular Interactions of Peptides With Gold, Palladium, and Pd-Au Bimetal Surfaces in Aqueous Solution. J. Am. Chem. Soc. 2009, 131, $9704-$ 9714.

(45) Hoefling, M.; Monti, S.; Corni, S.; Gottschalk, K. E. Interaction of $\beta$-Sheet Folds With a Gold Surface. PLOS ONE 2011, 6, e20925.

(46) Patwardhan, S. V.; Emami, F. S.; Berry, R. J.; Jones, S. E.; Naik, R. R.; Deschaume, O.; Heinz, H.; Perry, C. C. Chemistry of Aqueous Silica Nanoparticle Surfaces and the Mechanism of Selective Peptide Adsorption. J. Am. Chem. Soc. 2012, 134, 6244-6256.

(47) Feng, J.; Pandey, R. B.; Berry, R. J.; Farmer, B. L.; Naik, R. R.; Heinz, H. Adsorption Mechanism of Single Amino Acid and Surfactant Molecules to Au\{111\} Surfaces in Aqueous Solution: Design Rules For Metal-Binding Molecules. Soft Matter 2011, 7, 2113-2120.

(48) Durell, S. R.; Brooks, B. R.; Ben-Naim, A. Solvent-Induced Forces Between Two Hydrophilic Groups. J. Phys. Chem. 1994, 98, 2198-2202.

(49) Kurrat, R.; Prenosil, J. E.; Ramsden, J. J. Kinetics of Human and Bovine Serum Albumin Adsorption at Silica-Titania Surfaces. J. Coll. Int. Sci. 1997, 185, 1-8.

(50) Carter, D. C.; Ho, J. X. Structure of Serum Albumin. Adv. Protein Chem. 1994, 45, 153-203. 
(51) Jachimska, B.; Kozlowska, A.; Pajor-Swierzy, A. Protonation of Lysozymes and Its Consequences For the Adsorption Onto a Mica Surface. Langmuir 2012, 28, $11502-11510$.

(52) Hartvig, R. A.; Weert, M.; Østergaard, J.; Jorgensen, L.; Jensen, H. Protein Adsorption at Charged Surfaces: The Role of Electrostatic Interactions and Interfacial Charge Regulation. Langmuir 2011, 27, 2634-2643.

(53) Jachimska, B.; Tokarczyk, K. Combining Surface Plasmon Resonance and Quartz Crystal Microbalance to Determine Hydration of Dendrimer Monolayers. J. Phys. Chem. C 2016, 120, 19678-19685.

(54) Sander, M.; Madliger, M.; Schwarzenbach, R. P. Adsorption of Transgenic Insecticidal Cry1Ab Protein to SiO2. 1. Forces Driving Adsorption. Environ. Sci. Technol. 2010, 44, 8870-8876.

(55) Su, T. J.; Lu, J. R.; Thomas, R. K.; Cui, Z. F. Effect of pH on the Adsorption of Bovine Serum Albumin at the Silica/Water Interface Studied by Neutron Reflection. $J$. Phys. Chem. B 1999, 103, 3727-3736.

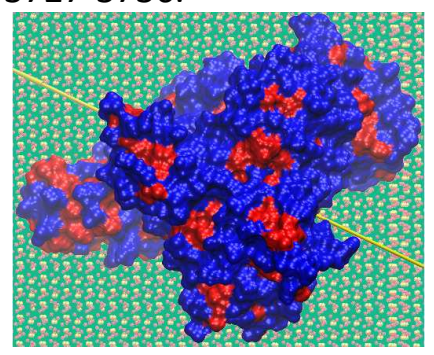

TOC Graphic 


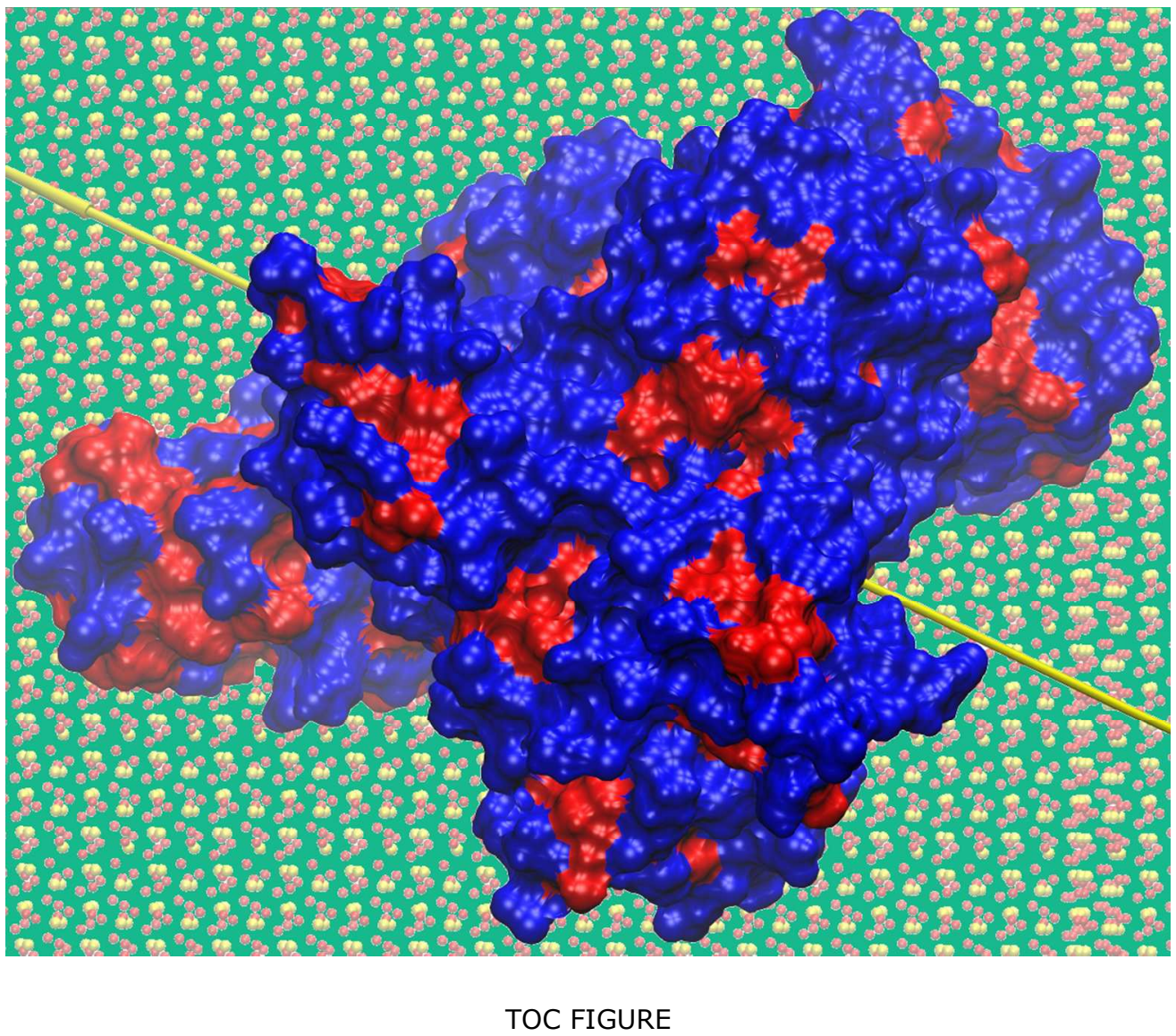

$318 \times 256 \mathrm{~mm}(97 \times 98 \mathrm{DPI})$ 